Research Article

\title{
Fusion of Vibration and Current Signatures for the Fault Diagnosis of Induction Machines
}

\author{
Meng-Kun Liu $\mathbb{D}^{1,{ }^{1,2}}$ Minh-Quang Tran $\mathbb{D}^{1},{ }^{1}$ and Peng-Yi Weng ${ }^{1}$ \\ ${ }^{1}$ Department of Mechanical Engineering, National Taiwan University of Science and Technology, Taipei 10607, Taiwan \\ ${ }^{2}$ Center for Cyber-Physical System Innovation, National Taiwan University of Science and Technology, Taipei 10607, Taiwan \\ Correspondence should be addressed to Meng-Kun Liu; mkliu@mail.ntust.edu.tw
}

Received 19 April 2019; Revised 10 July 2019; Accepted 24 July 2019; Published 19 September 2019

Academic Editor: Luca Pugi

Copyright ( $\odot 2019$ Meng-Kun Liu et al. This is an open access article distributed under the Creative Commons Attribution License, which permits unrestricted use, distribution, and reproduction in any medium, provided the original work is properly cited.

Induction machines are widely used in the industry as one of the major actuators, such as water pumps, air compressors, and fans. It is necessary to monitor and diagnose these induction motors to prevent any sudden shut downs caused by premature failures. Numerous fault detection and isolation techniques for the diagnosis of induction machines have been proposed over the past few decades. Among these techniques, motor current signature analysis (MCSA) and vibration analysis are two of the most common signal-based condition monitoring methods. They are often adopted independently, but each method has its strengths and weaknesses. This research proposed a systemic method to integrate the information received from the vibration and current measurements. We applied the wavelet packet decomposition to extract the time-frequency features of the vibration and current measurements and used the support vector machines as classifiers for the initial decision-making. The significant features were identified, and the performances of several classifiers were compared. As a result, the decision-level sensor fusion based on the Sugeno fuzzy integral was proposed to integrate the vibration and current information to improve the accuracy of the diagnosis.

\section{Introduction}

Rotary equipment driven by electromechanical systems such as an induction motor has been widely used in the industry because of its simple structure, low cost, and easy maintenance, and for this specific industry, the maintenance cost could ramp up to $60 \%$ of the goods produced [1]. Traditional maintenance management has applied a time-driven task, such as preventive maintenance, which repairs or rebuilds the machine based on the schedule determined by the meantime-to-failure (MTTF) statistic. However, these statistics vary greatly according to the operational condition and plant-specific variables, rendering the preventive maintenance strategy inefficient. A recent survey shows that onethird of all maintenance costs are wasted as a result of unnecessary or improperly carried out maintenance [1]. As a result, the contemporary maintenance management shifts to a predictive maintenance, which regularly monitors the machine's condition to improve the productivity, the product quality, and the overall effectiveness of the manufacturing and production plant. The foundation of the predictive maintenance relies on the early detection of the potential failures. For the induction motor-driven equipment, it means to detect the premature failures such as the bearing defect, stator winding shortage, broken rotor bar, airgap eccentricity, and coupling misalignment. These premature motor failures could generate heat, reduce output torque, and increase the energy consumption. The early detection and diagnosis of the induction motor could prevent the sudden failure, conserve energy, and increase the mean time between failures (MTBF).

Because most of the plant equipment is mechanical, vibration analysis has been adopted as one of the most oftenused condition monitoring techniques [2]. This mainly applies accelerometers to the equipment to measure the velocity signal. The criterion, such as the ISO 10816, uses the root mean square value of the vibration velocity to define the degree of machine abnormality. However, the ISO 10816 only defines the degree of machine abnormality in general, and it does not specify the types and causes of the faults. 
Hence, recent vibration analysis applied the Fourier spectrum to define the characteristic frequencies of the rotor machine faults such as the bearing faults, shift imbalance, loose screw, and transmission belt faults [1, 3-5]. Most previous studies have focused on the frequencies caused by the bearing defects, which make up almost half of the rotor machinery faults. The premature bearing failures are due to the deficiencies of lubrication, loading, transmission design, and manufacturing. Since the vibration of the bearing defect is transient and nonstationary, several researches have adopted the envelope analysis, which applies the upper envelopes to contain the vibration waveforms, to identify the frequency of the shockwaves generated by the bearing defect [6-8]. Time-frequency analysis methods such as the shorttime Fourier transform (STFT), the Hilbert spectrum, the discrete wavelet transform (DWT), and the wavelet packet decomposition (WPD) were also used to analyse the time and frequency domains of the vibration signal simultaneously [9]. By decomposing the time-domain signal into multiple frequency components, the DWT could reflect the induction motor faults in terms of the power spectral density within each bandwidth [4]. The wavelet decomposition was used to filter the vibration signal contaminated by the noise, and the energy of the WPD coefficients could be used to determine the condition of the rolling bearing [10-12]. Recently, WPD was combined with kurtosis to overcome the shortcoming of the original kurtogram [13-15]. The improved kurtogram which adopts WPD as the filter of the kurtogram was proofed to obtain clear fault characteristics with a higher signal-to-noise ratio than the original kurtogram $[13,14]$. The enhanced kurtogram was proposed to quantify the power spectrum of the envelope of the signals extracted from the wavelet packet coefficients [15]. It helps to determine the location of resonant frequency bands for further envelope analysis. Several studies have applied classifiers to distinguish the fault components. The radial basis function neural network (RBFNN) and the Bayesian classifiers were applied to analyse the features extracted from the WPD coefficients. The accuracies of classification with regard to multiple mother wavelets were discussed and compared $[16,17]$. The vibration signal of the bearing defect was denoised by the wavelet transform, and the bearing condition was classified by the support vector machine, which was reported to be more efficient and accurate than the artificial neural network (ANN) and other classifiers $[18,19]$.

Nevertheless, the vibration signal was easily contaminated by noises and disturbances, and the resonance of the equipment could therefore undermine the judgement of the diagnosis. To compensate the difficult identification of the electrical faults by the vibration analysis, the motor current signature analysis (MCSA) can attract much more attention. It measures the three-phase currents of the induction motor, and the Fourier spectrum of the current could reflect both the mechanical and electrical faults. In the definition of ISO 20958, the MCSA is one of the electrical signature analysis (ESA) methods. When the induction motor faults occur, they would cause the variation of the airgap during the radial rotor movement, influence the flux density, and change the three-phase stator currents. The fault-induced frequencies on the current spectrum would emerge as symmetric side lobes alongside the VFD frequency, a phenomenon called the frequency modulation [20-22]. These fault-induced frequencies could be calculated by formulas based on the motor specifications such as the number of rotor slots, motor slips, and the nominal radial airgap length [23, 24]. However, these specifications are sometimes difficult to retrieve in a real-world application. By measuring the current and voltage signals, it could detect the faults induced by the electrical components such as the power converter, inverter, and variable frequency driver. The steady-state voltage and current waveforms were measured, and a complex-valued ANN was used to identify the abnormal parameter values of the PWM DC-DC converter [25]. The voltage and current waveforms were used to derive the parameters within the Class $\mathrm{E}$ resonant inverter and conducted the reliability analysis [26]. In addition, the current spectrum would be affected by the input voltage of the motor, thereby generating a false alarm. Hence, the application of the MCSA relies heavily on the experienced engineers. Like vibration analysis, several researches have applied the Fourier spectrum and time-frequency methods such as STFT and WPD to analyse the current signal $[27,28]$. The energy of the WPD coefficients of the induction motor current was used to differentiate the fault condition of a broken rotor bar and an airgap eccentricity [29]. The power spectrum density of the multiresolution components calculated by the wavelet transform was used to identify various machinery faults $[30,31]$. The classifiers were also used to identify the faulty features within the current signal. The principal component analysis (PCA) and the kernel PCA were used to select the beneficial features for the classification. Several wavelet and SVM applications were used in the classification of the bearing faults of a rotary machine [32-34].

Recently, it was reported that the diagnosis based on a single type of sensor could misjudge the machine's condition. An in-service wind turbine train drive was originally misdiagnosed as bearing faults by the vibration analysis but was later identified as a mechanical imbalance by the current signature analysis [35]. The combination of multiple sensors is needed for predictive maintenance to accurately determine the operational condition and to isolate the root cause of the machine faults. The multiclass SVM and five different data fusion methods were used to detect the machinery fault, and the result indicated that the one-againstone SVM with one of the fusion schemes could acquire the best performance [36]. Classifiers such as the SVM, linear discriminant analysis (LDA), K-nearest neighbours (kNN), and the adaptive resonance theory-Kohonen neural network (ART-KNN) were used to identify the motor faults based on the transient current signal, and the performance of the two fusion schemes, the Bayesian belief fusion and the multiagent fusion, was compared [37]. The redundant features from the vibration signal and load cell data were eliminated by the PCA, and the k-NN was used to classify the ball bearing condition. It was reported that the load cell is powerful enough to detect the healthy ball bearings from the 
defected ones and that the accelerometer is useful to detect the location of the fault [38]. Twelve time-domain features were extracted from eight sensor measurements, and the SVM was used to identify the gear fault, bearing fault, and rotor crack [39]. The fuzzy c-means analysis was employed to establish the mappings between the features and the given faults. These features were fused at the feature and decision levels by the fuzzy integral data fusion to diagnose the induction motor faults [40].

In this study, we try to integrate the information received from the vibration and current signals. Five induction machine conditions including both mechanical and electrical faults were presented in the experiment. The vibration and current signals during the operation were measured, and the time-frequency features were extracted by applying statistical indexes to the WPD coefficients. The vibrationbased diagnosis and current-based diagnosis were conducted, and the performances of multiple classifiers were compared. As a result, a decision-level sensor fusion diagnosis scheme was proposed to integrate both the vibration and current information to improve the accuracy of diagnosis.

\section{Research Methods}

2.1. Wavelet Packet Decomposition. Since the Fourier transform is insufficient when analysing the transient and nonlinear features generated by the induction motor faults, the wavelet analysis is used to capture the time-frequency characters of the vibration and current signals. By dilating and translating the mother wavelet, the time-frequency analysis could be realized. Wavelet analysis has a good frequency resolution at the low frequency range and a good time resolution at the high frequency range. The discrete form of the continuous wavelet transform can be represented as

$$
\operatorname{DWT}(j, k)=\frac{1}{\sqrt{2^{j}}} \sum_{n} x(n) \Psi\left(\frac{n-k 2^{j}}{2^{j}}\right),
$$

where $j, k, n \in \mathbb{Z}$ and $\Psi(n)$ is the mother wavelet. The DWT could also be realized by applying a series of high-pass and low-pass filter pairs, as this transforms the time-domain signal into the approximation coefficients and detail coefficients. Because the DWT only decomposes the lower half of the frequency spectrum, it has a limited frequency resolution regarding the high-frequency components. In point of fact, the WPD applies the filter pairs to both the approximation and detail coefficients. Thus, it has a better frequency resolution at the high-frequency spectrum than the DWT. The WPD can be defined as

$$
W_{j, k}^{n}(t)=2^{j / 2} W^{n}\left(2^{j} t-k\right),
$$

where the integers $j$ and $k$ are the index scale and translation operations. The index $n$ is considered an operation modulation parameter or an oscillation parameter [41, 42]. An example of three-layer WPD is shown in Figure 1.

2.2. Feature Extraction. Statistical features which are usually used for the induction motor fault diagnosis are extracted

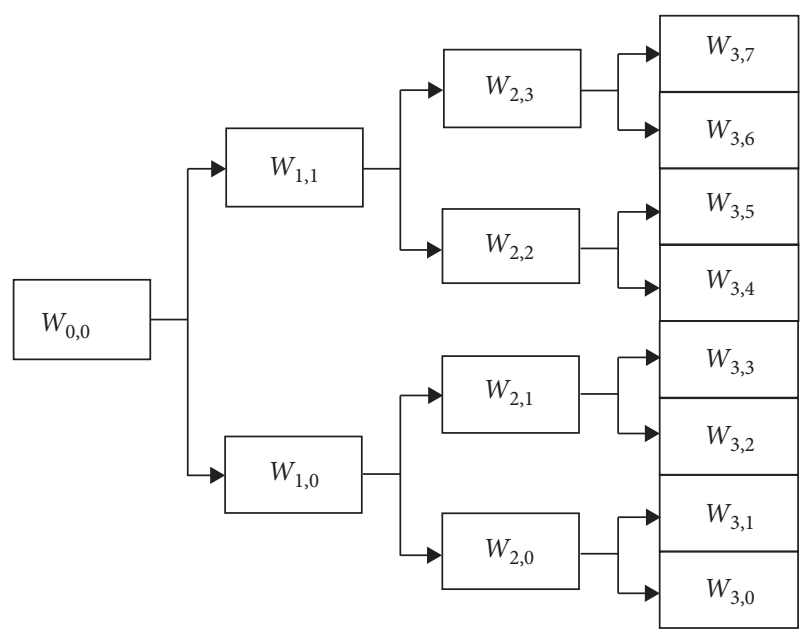

Figure 1: Three-layer WPD.

from WPD coefficients. The statistical indexes such as kurtosis (KU), skewness (SK), standard deviation (SD), root mean square (RMS), maximum value (MAX), and waveform factor (WF) were applied to the wavelet coefficients related to the specific fault characteristic frequencies. The indexes were reported as the most prominent conventional timedomain features which were applied for condition monitoring of typical rolling element bearings [43]. Root mean square and standard deviation of vibration signals were increased when the faults developed, while the kurtosis and skewness indexes are usually used to examine the probability density function of the signal [44]. The waveform factor shows the value of the object's shape. In this study, variance (VAR), mean (ME), and crest factor (CF) were also applied so that there are totally nine features. These statistical indexes are defined and listed in Table 1. After all the features are extracted, the feature selection method is used to search significant features and remove irrelevant or redundant features.

2.3. Support Vector Machine. A support vector machine is a powerful machine learning technique for data classification. The concept is to calculate the hyperplane which separates two different classes of testing samples. Afterwards, the optimal hyperplane is used to find the maximum margin which separates two different classes of the closest data points $[18,42]$. The equation for the hyperplane can be defined as

$$
\mathbf{f}(x)=\beta^{\mathrm{T}} x+\beta_{0},
$$

where $\beta$ is the weight vector and $\beta_{0}$ is the bias. The requirements for the hyperplane are decided based on the constraints to classify all the training examples $x_{i}$ correctly:

$$
\begin{cases}\min _{\beta, \beta_{0}} & L(\beta)=\frac{1}{2}\|\beta\|^{2} \\ \text { subject to } & y_{i}\left(\beta^{\mathrm{T}} x+\beta_{0}\right) \geq 1, \quad \forall i,\end{cases}
$$

where $y_{i}$ represents the labels of the training examples. 
TABle 1: Statistical indexes.

\begin{tabular}{lrr}
\hline $\mathrm{KU}=(1 / n) \sum_{i=1}^{n}\left(x_{i}-\bar{x}\right)^{4} /\left((1 / n) \sum_{i=1}^{n}\left(x_{i}-\bar{x}\right)\right)^{2}$ & $\mathrm{SK}=(1 / n) \sum_{i=1}^{n}\left(x_{i}-\bar{x}\right)^{3} /\left((1 / n) \sum_{i=1}^{n}\left(x_{i}-\bar{x}\right)^{2}\right)^{3 / 2}$ & $\mathrm{SD}=\sqrt{(1 / n) \sum_{i=1}^{n}\left(x_{i}-\bar{x}\right)^{2}}$ \\
$\mathrm{RMS}=\sqrt{(1 / n) \sum_{i=1}^{n} x_{i}^{2}}$ & $\mathrm{MAX}=\max (x)$ & $\mathrm{WF}=(1 / \bar{x}) \sqrt{(1 / n) \sum_{i=1}^{n} x_{i}^{2}}$ \\
$\mathrm{VAR}=(1 / n) \sum_{i=1}^{n}\left(x_{i}-\bar{x}\right)^{2}$ & $\mathrm{ME}=(1 / n) \sum_{i=1}^{n} x_{i}$ & $\mathrm{CF}=\max (x) / \sqrt{(1 / n) \sum_{i=1}^{n} x_{i}^{2}}$ \\
\hline
\end{tabular}

$\bar{x}$ is the average of the data, and $n$ is the sample size.

2.4. Fuzzy Integrals of Data Fusion. The fuzzy integral considers the objective evidence supplied by each information source (called the h-function) and the expected worth of each subset of information sources (via a fuzzy measure) in its decision-making process [45]. The fuzzy measure considers the generalized measures in which the additive property is replaced by the weaker property of the monotonicity. Let $X$ be a finite set of sources:

$$
X=\left\{x_{1}, x_{2}, \ldots, x_{n}\right\} .
$$

The set generated by $X$ is $\left\{\phi,\left\{x_{1}\right\},\left\{x_{2}\right\},\left\{x_{1}\right.\right.$, $\left.\left.x_{2}\right\}, \ldots, X\right\}=\Omega$. A fuzzy measure is defined as a function $g: \Omega \longrightarrow[0,1]$ which satisfies the following constraints:

$$
\begin{cases}g(\phi)=0, & g(X)=1, \\ g(A) \leq g(B) \leq 1, & \text { if } A \subseteq B \subseteq X,\end{cases}
$$

where $A$ and $B$ represent two disjoint sets. The set $A$ is the subset of the set $B$, and the set $B$ is the subset of the finite set $X$. The subsets $A$ and $B$ are used to calculate the Sugeno fuzzy measures. A fuzzy measure $g$ is called a Sugeno measure ( $g_{\lambda}$-fuzzy measure) if it additionally satisfies the following properties: $A \subseteq X, B \subseteq X$, and $A \cap B=\phi$; it therefore becomes

$$
g_{\lambda}(A \cup B)=g_{\lambda}(A)+g_{\lambda}(B)+\lambda g_{\lambda}(A) g_{\lambda}(B), \quad \lambda>1 .
$$

The value of $\lambda$ for any Sugeno fuzzy measure can be solved by the following equation:

$$
1+\lambda=\prod_{i=1}^{n}\left(1+\lambda g^{i}\right), \quad g_{\lambda}(X)=1 .
$$

The fuzzy integral is independently defined by Sugeno which is a nonlinear function defined in the fuzzy measure. The general form of the fuzzy integral is defined as [46]

$$
\int_{A} h(x) \circ g(\cdot)=\sup _{\alpha \in[0,1]}\left[\min \left(\alpha, g\left(A \cap F_{\alpha}\right)\right)\right],
$$

where $F_{\alpha}=\{x \mid h(x) \geq \alpha\}$. For the finite case, supposing $h\left(x_{\pi 1}\right) \geq h\left(x_{\pi 2}\right) \geq \cdots \geq h\left(x_{\pi n}\right)$, the fuzzy integral becomes

$$
\int_{A} h(x) \circ g(\cdot)=\max _{i=1}^{n}\left[\min \left(h\left(x_{\pi i}\right), g\left(A_{i}\right)\right)\right],
$$

where $A_{i}=\left\{x_{\pi 1}, x_{\pi 2}, \ldots, x_{\pi n}\right\}, \quad i=1, \ldots, n$.

2.5. Data Fusion Strategy for Fault Diagnosis. A fusion strategy of vibration and current signature for the fault diagnosis of induction machines is illustrated in Figure 2. Firstly, vibration-based diagnosis and current-based diagnosis are conducted to generate the initial decisions based on the vibration and current signals, respectively. Both of them apply statistical indexes to the WPD coefficients related to specific bandwidths to generate features for the support vector machine. Secondly, a decision-level data fusion is proposed to integrate the result of initial decisions and generate the final diagnosis result. The detailed procedures are further described in Section 4.

\section{Experimental Setup}

3.1. Hardware Configuration. The experiment consists of a TECO AEHF 3-phase induction motor (1 HP, low-voltage squirrel cage), a TECO A510 series variable frequency drive (VFD), and an AHB-5 hysteresis brake. Two Benstone 786A accelerometers with a sampling rate of $51,200 \mathrm{~Hz}$ were located in the vertical and horizontal directions with respect to the motor nondrive end, as shown in Figure 3.

Five conditions were applied to this experiment such as the normal condition, broken rotor bar, misalignment, inner ring fault, and outer ring fault. The broken rotor bar was created by making eight drilling holes in the rotor, as shown in Figure 4. The inner ring and outer ring faults were created by using wire electrical discharge machining (WEDM) to make a groove of $0.2 \mathrm{~mm}$ depth and $0.2 \mathrm{~mm}$ width on each ring, as shown in Figure 5. The faulty bearing was assembled at the nondrive end, and the healthy bearing was installed at the drive end. The motor alignment condition is adjusted by laser alignment of the shaft instrument, as shown in Figure 6.

The rotation speed of the motor could be adjusted by changing the output frequency of the VFD. In this experiment, the VFD frequency was set to $55 \mathrm{~Hz}$, equivalent to a motor speed of $1650 \mathrm{rpm}$, and $50 \%$ of the nominal load was applied by the hysteresis brake. Hence, the actual rotation speed would be slower than $1650 \mathrm{rpm}$. The measured data included the three-phase voltage and current signals, the VFD output signal, and the signals from the two accelerometers. In each experiment, the raw data were acquired for 20 seconds. The actual rotation speed was fixed at $1618 \mathrm{rpm}$, equivalent to $26.97 \mathrm{~Hz}$. The deep groove ball bearings of type 6204-T1 were used in this experiment, and their specification was as listed in [47]. The experiment under each condition was repeated three times, as shown in Table 2.

\subsection{Selection of the Wavelet Function and Decomposition} Level. The selection of the wavelet function and decomposition level depends on the previous literatures and the evaluation of wavelet coefficients. The mother wavelet and the decomposition level for the vibration and current signals were determined by the same procedure, respectively. 


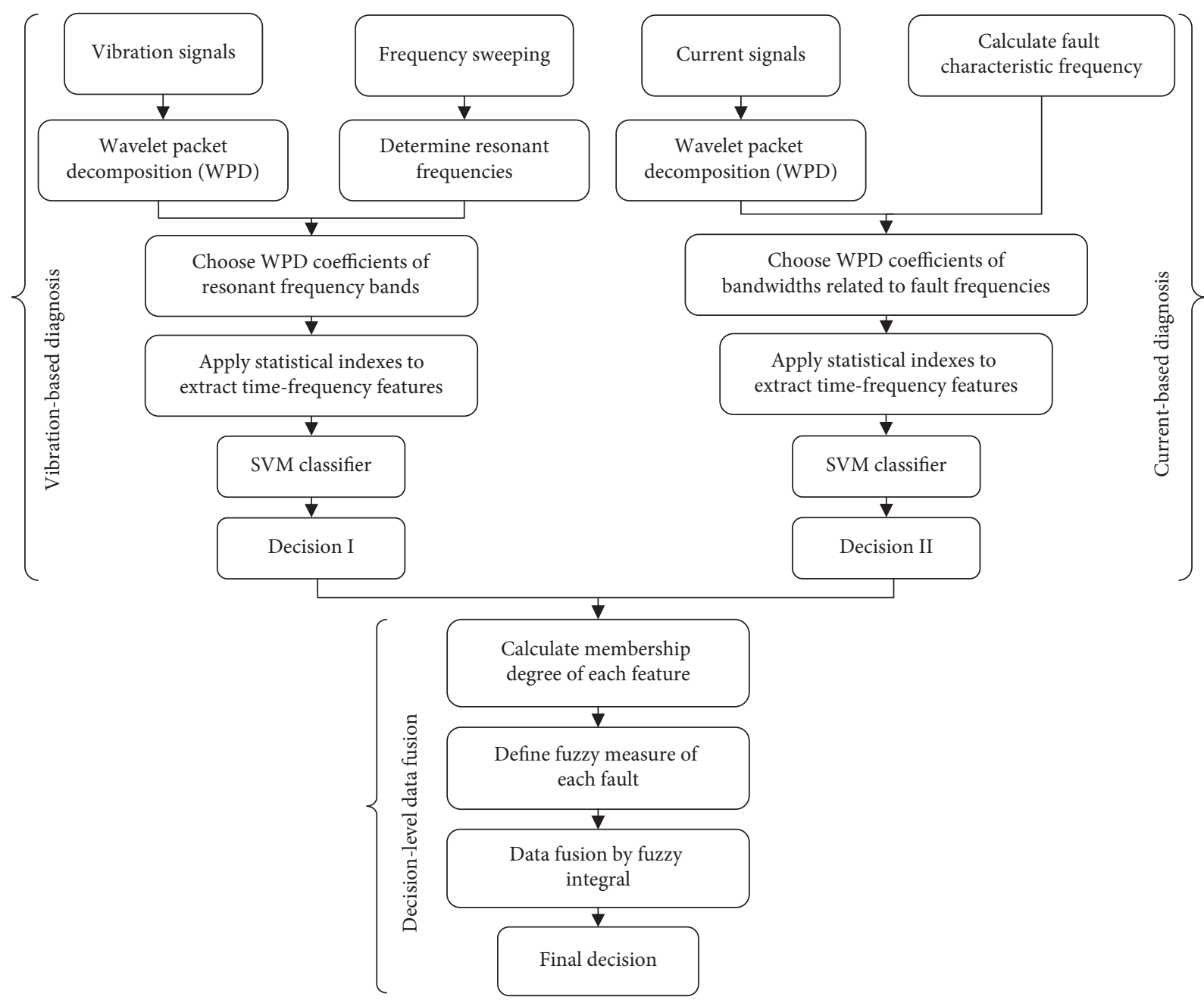

FIGURE 2: Flow chart of the proposed method.

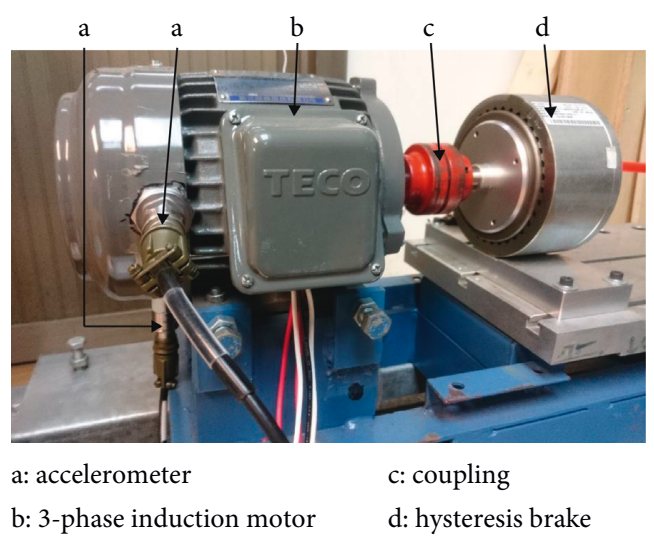

(a)

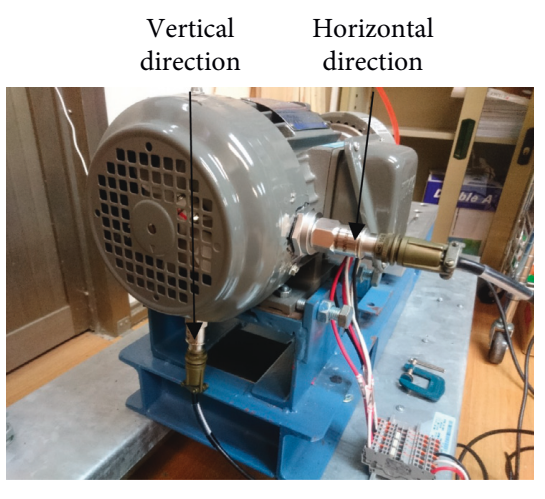

(b)

FIGURE 3: (a) Setup of the motor-driven rotary system. (b) Installation of accelerometers. a: accelerometer; b: 3-phase induction motor; c: coupling; d: hysteresis brake.

For the vibration signal analysis, the Daubechies and discrete Meyer wavelets were reported as the best wavelet functions in the previous literatures [48, 49]. A very narrow pulse-like antisymmetric wavelet, such as the Daubechies 10 wavelet or any higher-order wavelet of the Daubechies family, was found to perform well for the WPD. In this study, the kurtosis and crest factors of the wavelet coefficients regarding multiple wavelet functions and 


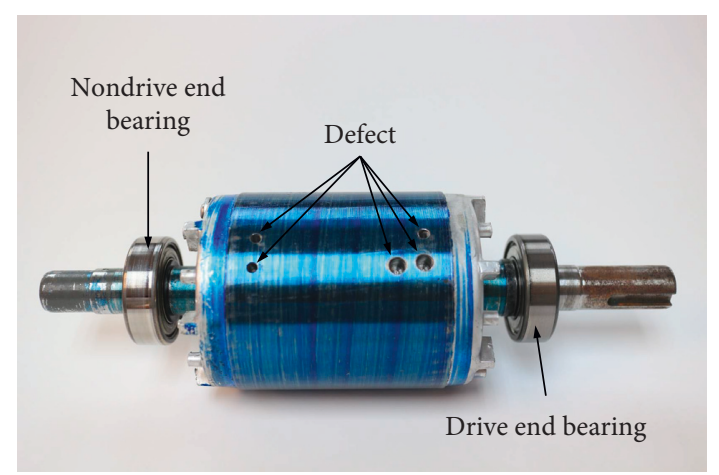

FIGURE 4: Broken rotor bar (defect created by drilling).

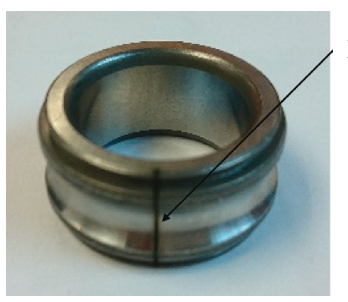

(a)

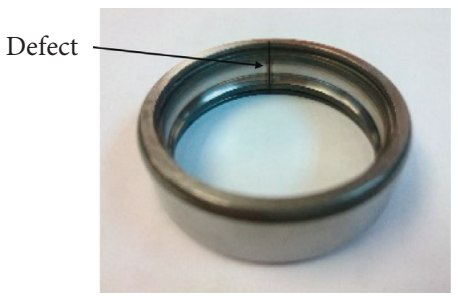

(b)
FIGURE 5: Bearing failure: (a) inner ring; (b) outer ring.

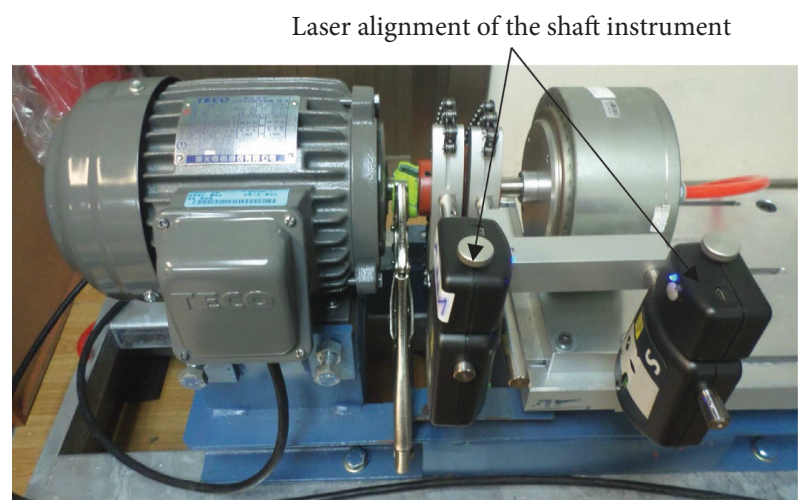

FIgURE 6: Setup of laser alignment of the shaft.

decomposition levels were calculated [50]. The kurtosis and crest factors of the $1^{\text {st }}$ level WPD coefficients using several wavelet functions such as Daubechies (db), symlets (sym), Coiflets (coif), biorthogonal (bior), and discrete Meyer (dmey) are compared in Figure 7. It can be seen that using the db20 mother wavelet could generate the most significant difference of crest factor between the normal and the bearing fault cases, as shown in Figure $7(b)$, meaning that the $d b 20$ wavelet could best reflect the difference between these two cases. Once the mother wavelet was chosen, the level of decomposition was determined following the same selection concept, which concludes that the $6^{\text {th }}$ level decomposition has the largest difference when applying the kurtosis and crest factors, as shown in Figure 8. Therefore, the db20 mother wavelet and the sixth-level decomposition were used for the vibration analysis in this study.
For the current signal analysis, a high frequency resolution wavelet function is required to emphasize the frequency characteristic of the signal. It was found that the dmey wavelet function has a better frequency resolution compared to $\mathrm{db}$, sym, and coif wavelets [51]. The same evaluation procedure was applied to select the wavelet function for the current analysis. It was shown that the dmey wavelet could generate the largest difference of kurtosis factors, as shown in Figure 9(a). Hence, the dmey function was chosen as the mother wavelet function when applying WPD to analyse the current signal.

The fault characteristic frequencies of the current signal were calculated as $f_{s}=55 \mathrm{~Hz}, F_{\mathrm{BRB}}=57.7 \mathrm{~Hz}, F_{\mathrm{MIS}}=81.9 \mathrm{~Hz}$, $F_{\mathrm{IRF}}=188.3 \mathrm{~Hz}$, and $F_{\mathrm{ORF}}=137.4 \mathrm{~Hz}$. To distinguish these frequencies successfully, the current signal was resampled at $1280 \mathrm{~Hz}$, and $8^{\text {th }}$ level decomposition of the WPD was applied. The frequency bandwidth was therefore $2.5 \mathrm{~Hz}$ per node, and it could successfully separate the characteristic frequency of each fault condition.

\section{Analysis and Discussion}

4.1. Vibration Analysis. For the vibration analysis, only the signals from the accelerometer in the vertical direction were considered. The time response, the frequency spectrum, and the time-frequency plot drawn by the WPD in the healthy, inner ring fault, and outer ring fault conditions are as shown in Figures 10-12. For the healthy condition, the frequency spectrum in Figure 10(b) indicates that there are two groups of frequencies located around $0-1000 \mathrm{~Hz}$ and $16000 \mathrm{~Hz}$, while the frequency of $16000 \mathrm{~Hz}$ is the VFD switching frequency. The information in the time-frequency plot in Figure 10(c) also shows a respectable agreement with the Fourier spectrum. When the bearings with the inner ring and outer ring defects were applied, respectively, the increase of vibration amplitude could be observed from the time response, as shown in Figures 11(a) and 12(a). However, as mentioned in the previous literatures, the shockwaves generated by the collision of the balls and the ring defect were difficult to identify. Both the Fourier spectrum and the time-frequency plot in Figures 11 and 12 indicated that the resonant frequencies around $2000 \mathrm{~Hz}-4000 \mathrm{~Hz}$ were triggered. To further analyse these resonant frequencies, the sixth-level WPD with the db20 mother wavelet was applied. It could be observed that the energy of the VFD frequencies was increased in the Fourier spectrum, and the bandwidth around $2000 \mathrm{~Hz}$ in the time-frequency plot shows periodic patterns, whose location is equivalent to the $59^{\text {th }}$ node in the sixth-level wavelet decomposition. Hence, the statistical indexes were applied to the $59^{\text {th }}$ node of the WPD to extract features for the vibration-based diagnosis.

4.2. Motor Current Signature Analysis. The current frequencies generated by a broken rotor bar $\left(F_{\mathrm{BRB}}\right)$, misalignment $\left(F_{\mathrm{MIS}}\right)$, inner ring defect $\left(F_{\mathrm{IR}}\right)$, and outer ring defect $\left(F_{\mathrm{OR}}\right)$ were calculated by the following equations [38]: 
TABle 2: Parameters of the experiment.

\begin{tabular}{ccccccc}
\hline No. & VFD (Hz) & Rotation speed $(\mathrm{Hz})$ & Resistance $(\%)$ & Failure mode & $\begin{array}{c}\text { Current characteristic } \\
\text { frequency }(\mathrm{Hz})\end{array}$ & $\begin{array}{c}\text { Vibration characteristic } \\
\text { frequency }(\mathrm{Hz})\end{array}$ \\
\hline 1 & 55 & 26.97 & 50 & Normal & 55 & 26.97 \\
2 & 55 & 26.97 & 50 & Broken rotor bar & 57.13 & N/A \\
3 & 55 & 26.97 & 50 & Misalignment & 82.5 & N/A \\
4 & 55 & 26.97 & 50 & Inner ring & 188.3 & 133.3 \\
5 & 55 & 26.97 & 50 & Outer ring fault & 137.43 & 82.43 \\
\hline
\end{tabular}

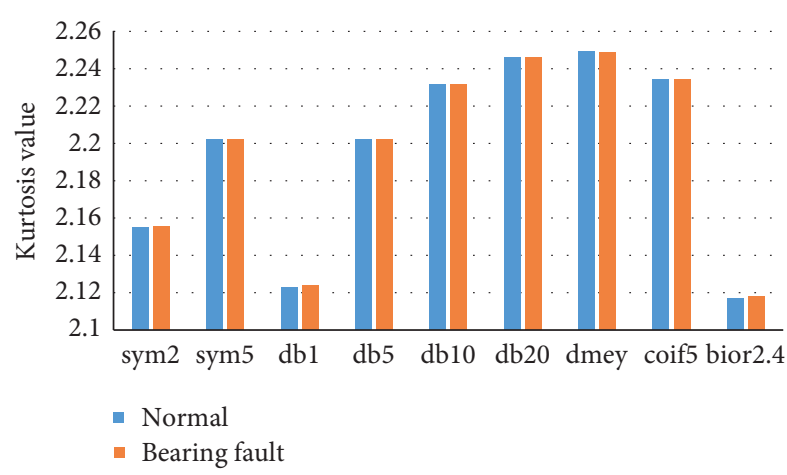

(a)

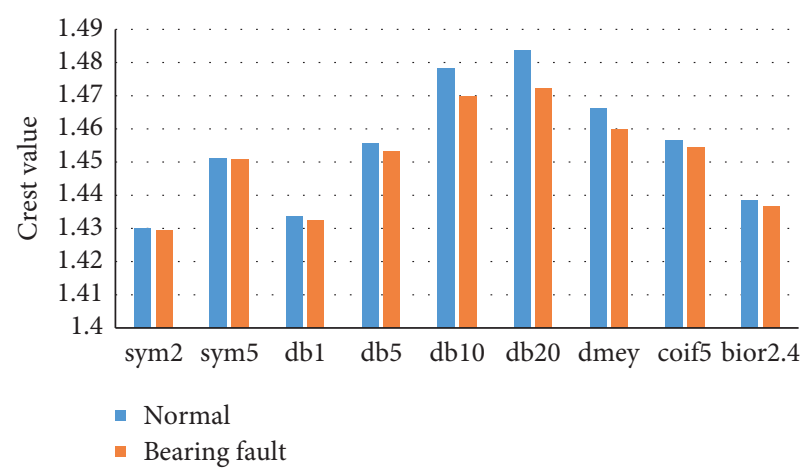

(b)

Figure 7: (a) Kurtosis factor and (b) crest factor of the vibration signal.

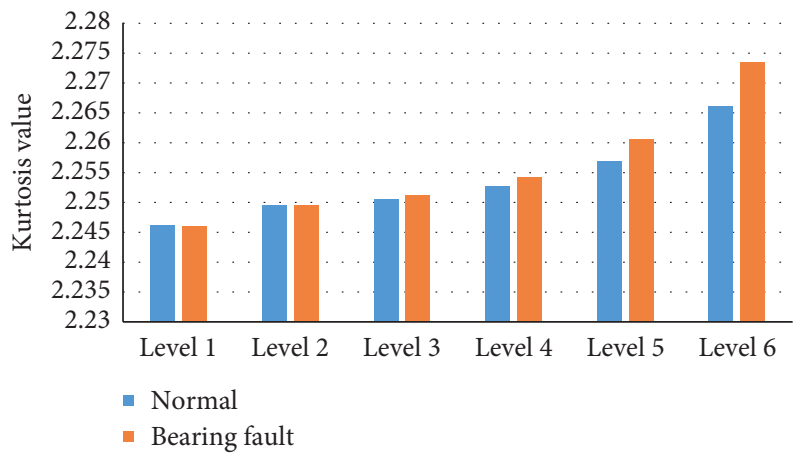

(a)

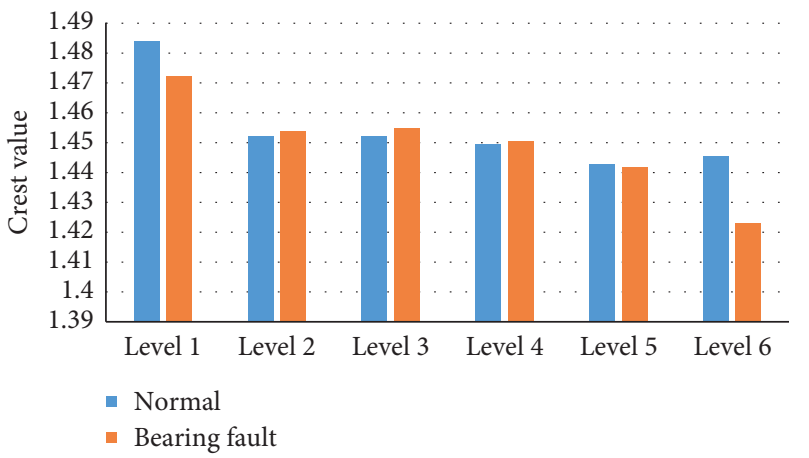

(b)

FIGURE 8: (a) Kurtosis factor and (b) crest factor of multiple-level WPD coefficients.

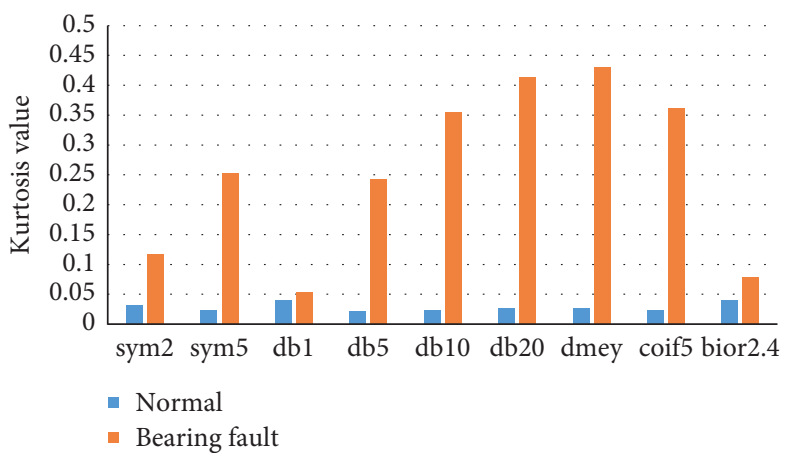

(a)

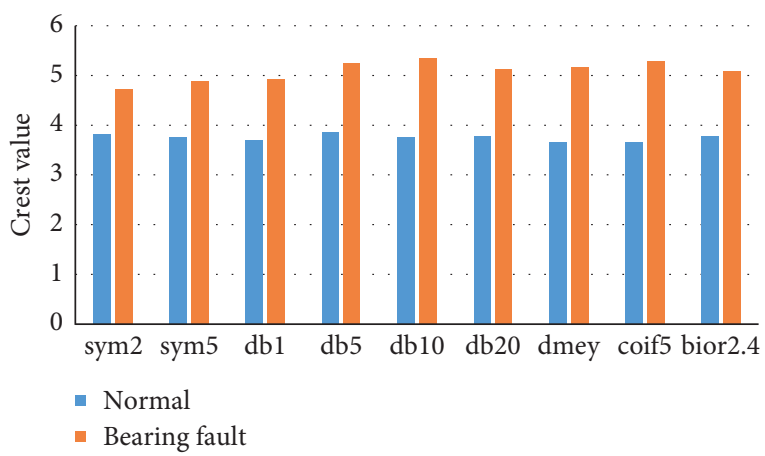

(b)

Figure 9: (a) Kurtosis factor and (b) crest factor of the current signal. 


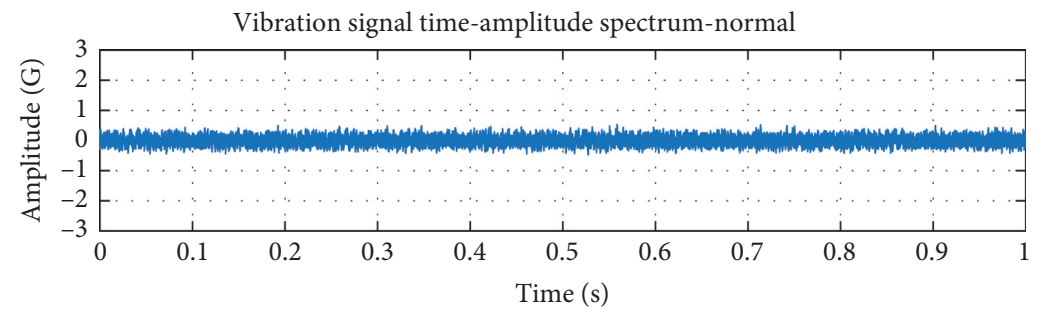

(a)

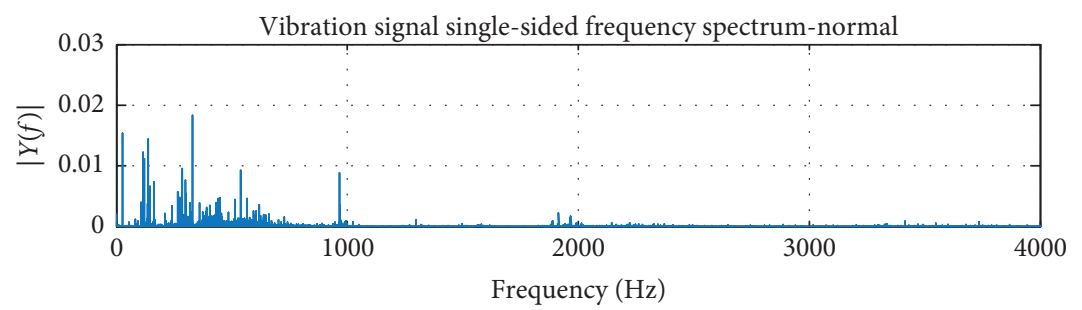

(b)

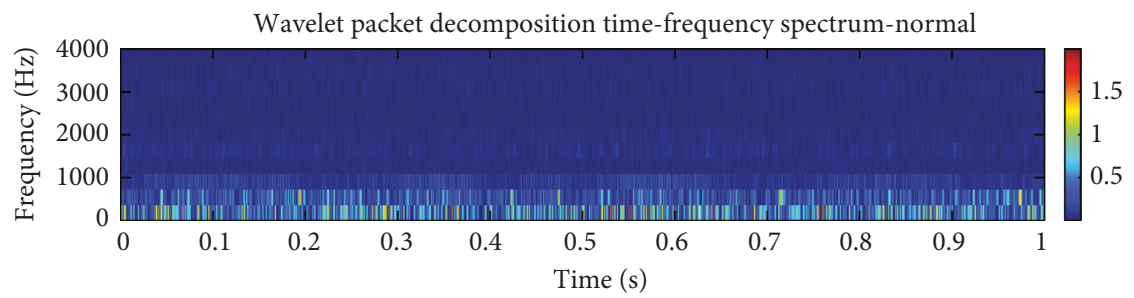

(c)

FIGURE 10: Vibration signal of the normal condition: (a) time-domain response; (b) FFT; (c) WPD.

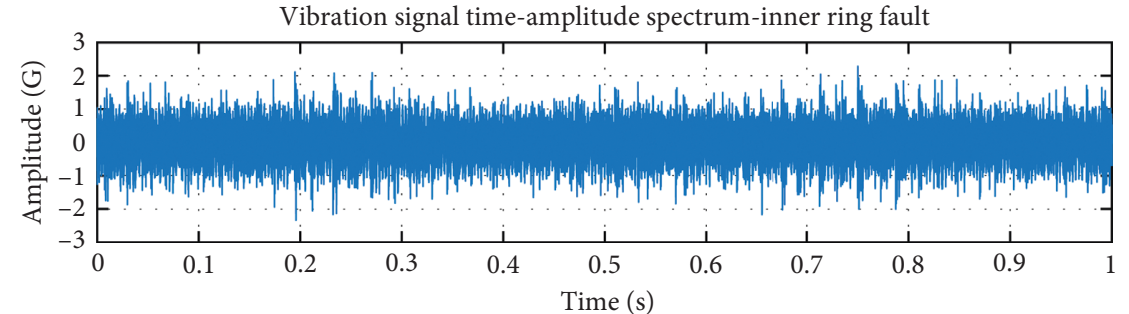

(a)

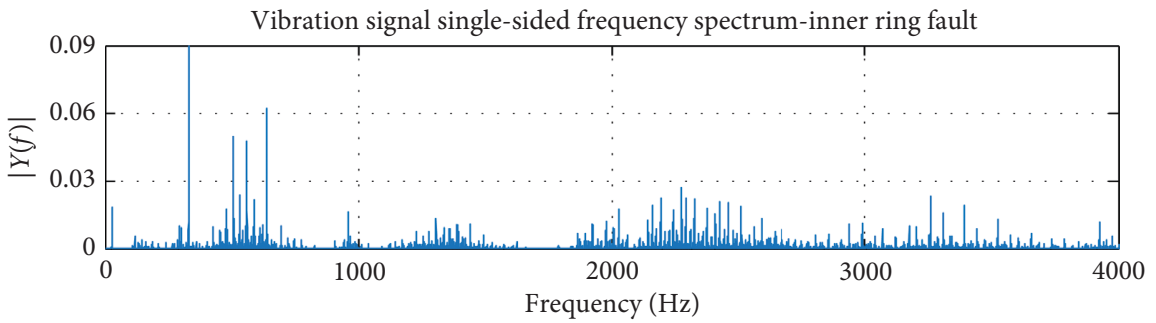

(b)

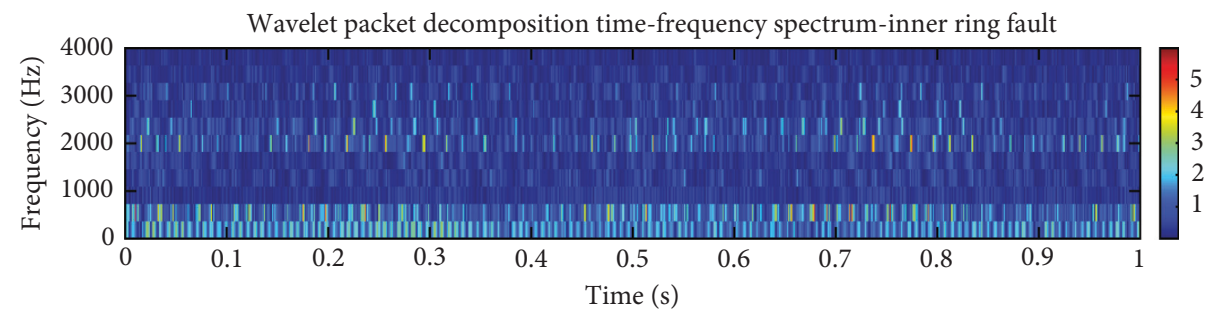

(c)

FIGURE 11: Vibration signal of the inner ring fault: (a) time-domain response; (b) FFT; (c) WPD. 


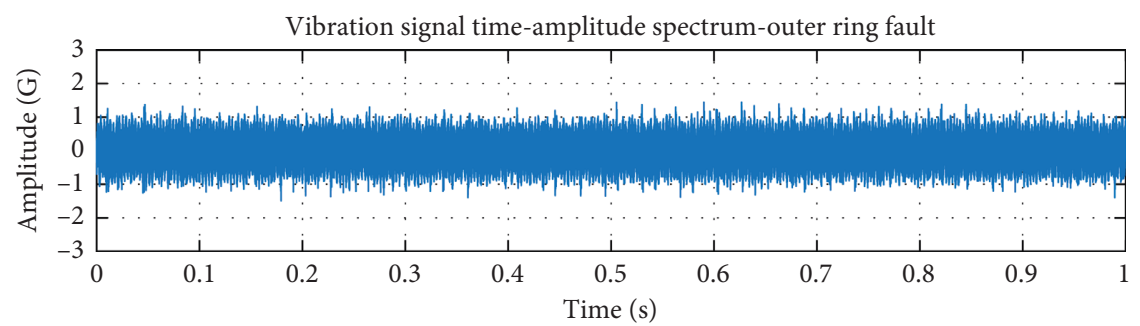

(a)

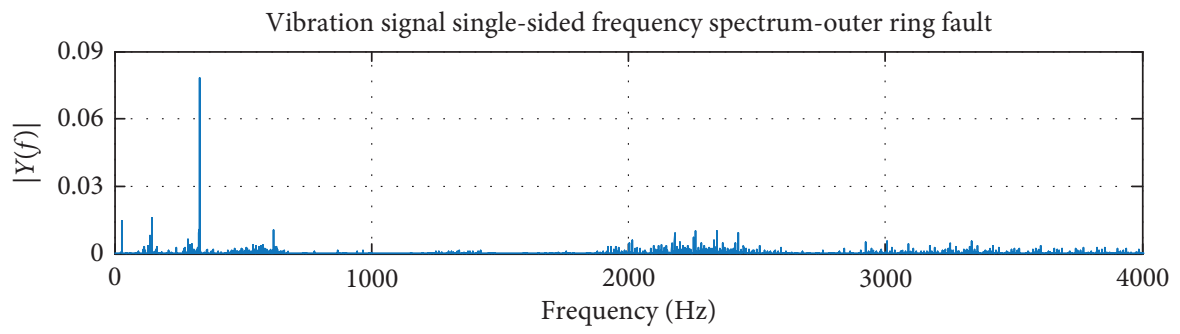

(b)

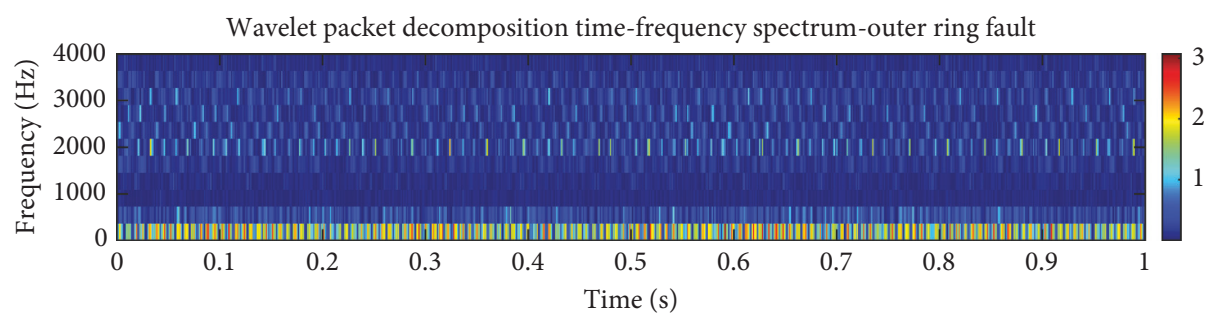

(c)

FIGURE 12: Vibration signal of the outer ring fault: (a) time-domain response; (b) FFT; (c) WPD.

$$
\begin{aligned}
& F_{\mathrm{BRB}}=(1 \pm 2 k s) f_{s}, \\
& F_{\mathrm{Mis}}=f_{s} \pm 0.5 f_{s}, \\
& F_{\mathrm{ORF}}=f_{s}+\frac{N_{B}}{2} F_{R}\left(1-\frac{D_{B} \cos (\theta)}{D_{P}}\right), \\
& F_{\mathrm{IRF}}=f_{s}+\frac{N_{B}}{2} F_{R}\left(1+\frac{D_{B} \cos (\theta)}{D_{P}}\right),
\end{aligned}
$$

where $f_{s}$ is the main current frequency caused by the VFD, $s$ is the slip between the rotor and the stator, and $k$ is an integer. It could be calculated that $f_{s}=55 \mathrm{~Hz}, F_{\mathrm{BRB}}=57.7 \mathrm{~Hz}, F_{\mathrm{MIS}}=81.9 \mathrm{~Hz}$, $F_{\mathrm{IRF}}=188.3 \mathrm{~Hz}$, and $F_{\mathrm{ORF}}=137.4 \mathrm{~Hz}$. The time response and the Fourier spectrum of the current signal under the normal condition are as shown in Figure 13. The main frequency of $54.9 \mathrm{~Hz}$ and the misalignment frequency of $81.9 \mathrm{~Hz}$ are observed in Figure 13(b), which indicates that the equipment has a slight degree of misalignment. According to the analysis method of the MCSA, the degree of the fault depends on the peak value difference between the main frequency and the fault characteristic frequency on the Fourier spectrum. However, in this case, we could define the peak difference $39.7 \mathrm{db}$ between $54.9 \mathrm{~Hz}$ and $81.9 \mathrm{~Hz}$ as the baseline of the normal condition.

To identify these frequencies successfully, the current signal was resampled at $1280 \mathrm{~Hz}$, and $8^{\text {th }}$ level decomposition of the WPD, which empirically adopted the discrete Meyer wavelet as the mother wavelet, was applied. The frequency bandwidth therefore was $2.5 \mathrm{~Hz}$ per node, and it could separate the characteristic frequency of each fault condition. Five sections of the wavelet coefficients related to $f_{s}, F_{\mathrm{BRB}}, F_{\mathrm{MIS}}, F_{\mathrm{ORF}}$, and $F_{\mathrm{IRF}}$ under the normal condition are as shown in Figure 14. Take the condition of a broken rotor bar for example; the additional periodic motion could be observed on the time response in Figure 15(a). This faulty condition could be further confirmed in Figure 15(b), which indicates a frequency modulation near the main frequency, a characteristic of the broken rotor bar. In addition, as shown in Figure 16, the wavelet coefficients corresponding to $55-57.5 \mathrm{~Hz}$ and $57.5-60 \mathrm{~Hz}$ indicate the distinct patterns when compared to the wavelet coefficients in the normal condition shown in Figure 14. Different patterns of the wavelet coefficients could also be observed regarding the misalignment defect, inner ring defect, and outer ring defect. As a result, the statistical indexes were applied to WPD coefficients related to aforementioned five fault characteristic frequencies calculated by the MCSA methods.

4.3. Feature Selection and Classification. Recursive feature elimination methods (RFEs) [52] were applied to select features for the vibration and current diagnoses. Nine features including kurtosis (KU), skewness (SK), standard deviation (SD), root mean square (RMS), maximum value (MAX), waveform factor (WF), variance (VAR), mean $(\mathrm{ME})$, and crest factor (CF) are ranked in Table 3. The index 


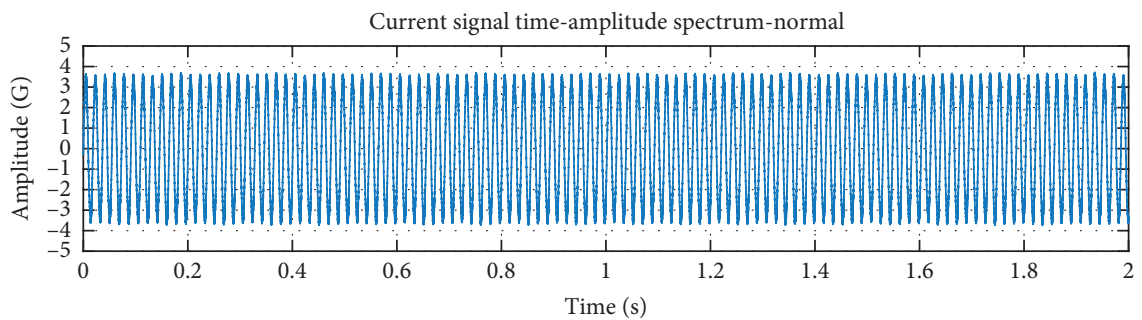

(a)

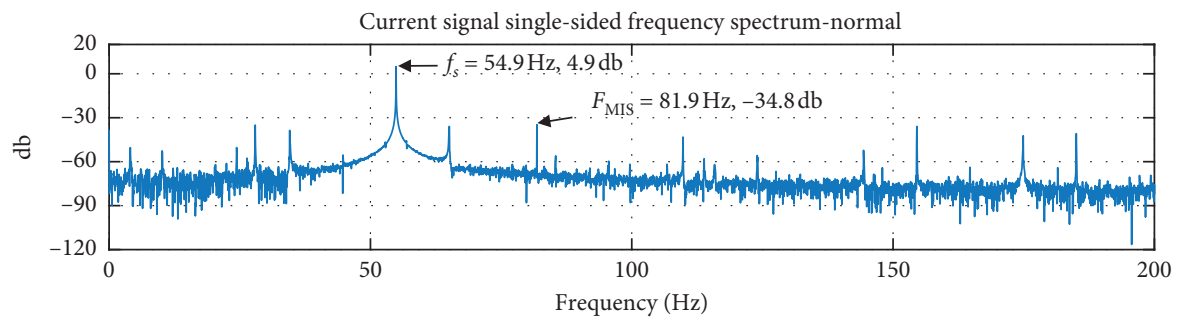

(b)

Figure 13: (a) Time response and (b) Fourier spectrum of the current signal under the normal condition.

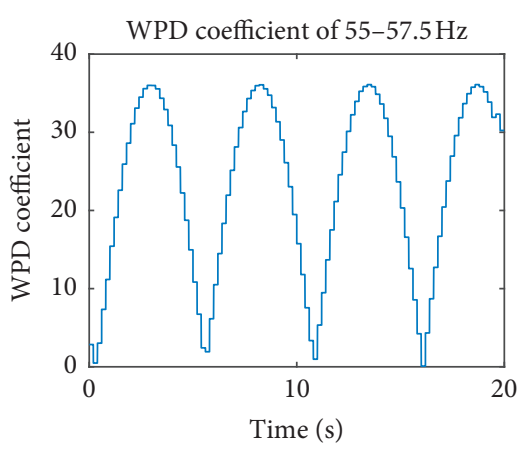

(a)

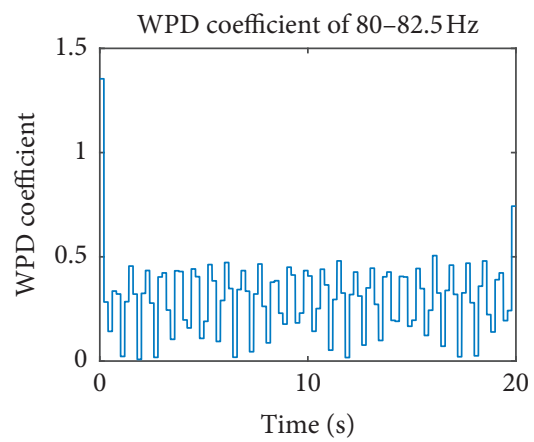

(c)

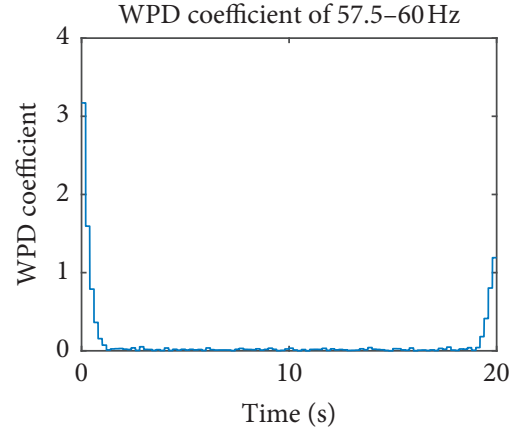

(b)

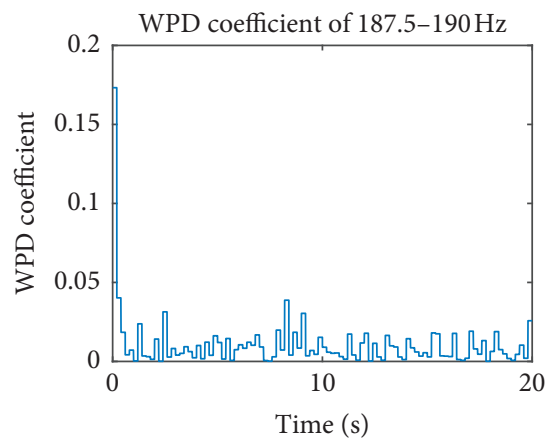

(d)

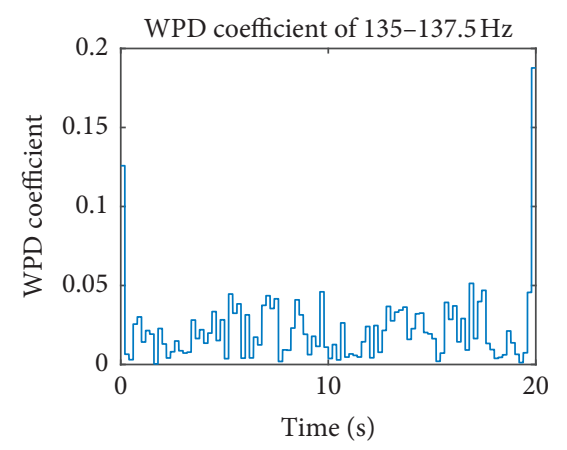

(e)

FIGURE 14: Wavelet coefficients related to (a) $f_{s}$, (b) $F_{\mathrm{BRB}}$, (c) $F_{\mathrm{MIS}}$, (d) $F_{\mathrm{ORF}}$, and (e) $F_{\mathrm{IRF}}$ under the normal condition. 


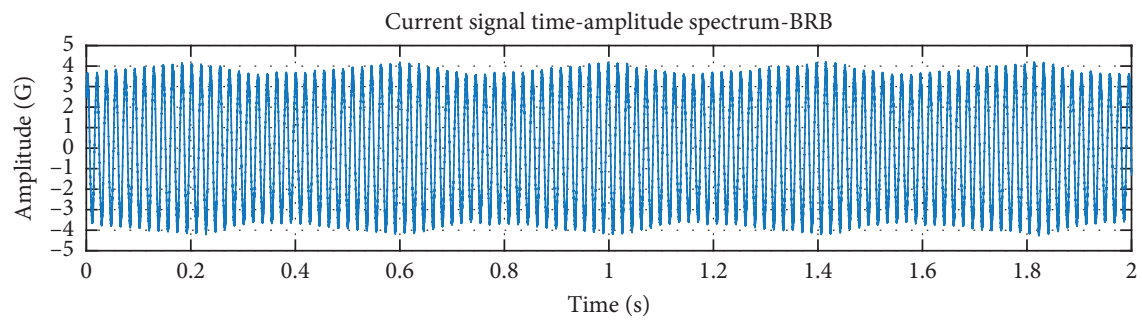

(a)

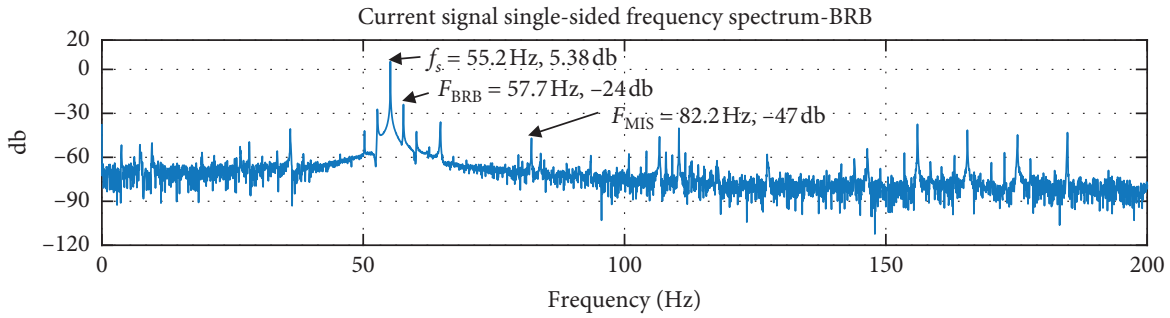

(b)

FIgURE 15: (a) Time response and (b) Fourier spectrum of the current signal under the broken rotor bar condition.

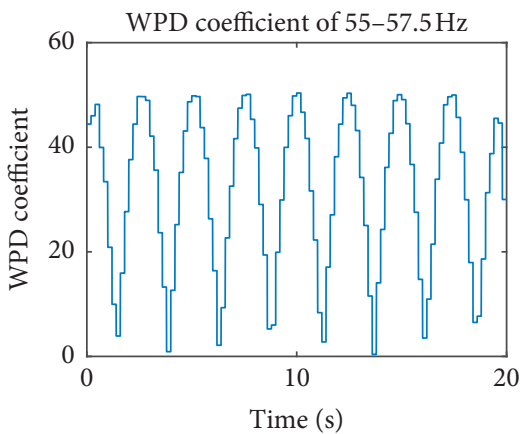

(a)

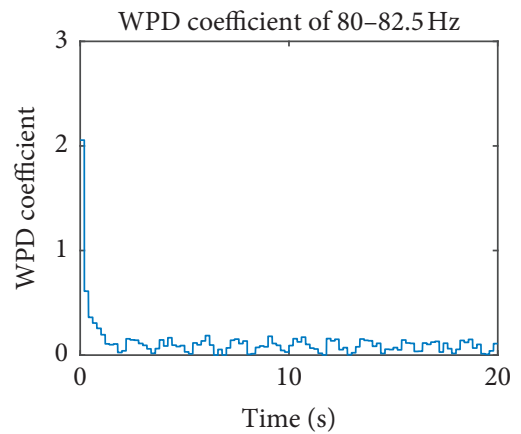

(c)

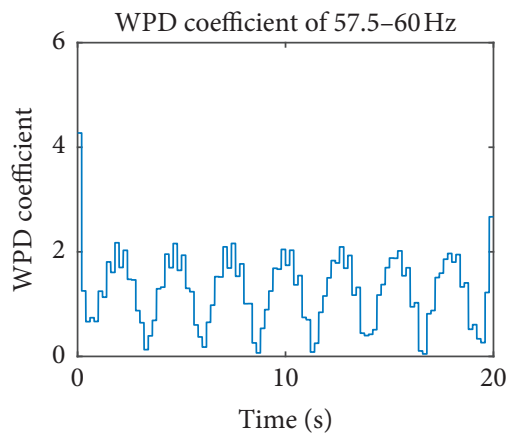

(b)

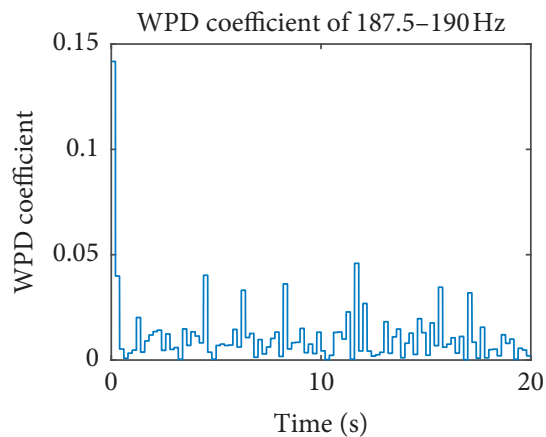

(d)

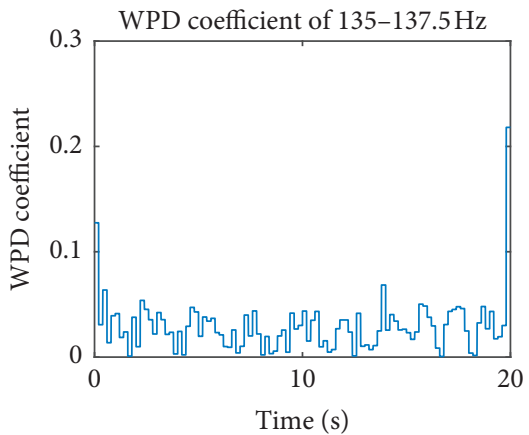

(e)

FIGURE 16: Wavelet coefficients related to (a) $f_{s}$, (b) $F_{\mathrm{BRB}}$, (c) $F_{\mathrm{MIS}}$, (d) $F_{\mathrm{ORF}}$, and (e) $F_{\mathrm{IRF}}$ under the broken rotor bar condition. 
TABLE 3: Feature selection by the RFE.

\begin{tabular}{lccccccccc}
\hline \multicolumn{10}{c}{ Feature ranking } \\
Signal & $\# 1$ & $\# 2$ & $\# 3$ & $\# 4$ & $\# 5$ & $\# 6$ & $\# 7$ & $\# 8$ & $\# 9$ \\
\hline Vibration & SK & MAX & CF & KU & WF & VAR & RMS & SD & ME \\
Current & SK & CF & WF & MAX & RMS & SD & ME & VAR & KU \\
\hline
\end{tabular}

with a higher ranking means it is a more significant feature to decision-making.

The SVM with linear kernel function was used to validate the result of feature selection by removing the least significant feature in sequence. Of the experiment data, $66.67 \%$ was used for training and the remaining $33.33 \%$ was used for testing. The classification accuracies of the vibration signal are listed in Table 4. It could be observed that the classification accuracy remains the same until only four features are left. Therefore, these four features, SK, MAX, CF, and KU, were adopted as the features of vibration analysis. In addition, it should be noted that the vibration analysis is most sensitive to the bearing defect because all the faulty conditions of the inner ring fault and the outer ring fault were identified accurately. The overall accuracy could only reach $65.56 \%$.

On the contrary, the classification accuracy of the current signal in Table 5 shows that it has the highest accuracy when eight features, SK, CF, WF, MAX, RMS, SD, ME, and VAR, are selected. So they were chosen as the features of current analysis. Meanwhile, it has the highest accuracy for the diagnosis of the broken rotor bar, and the overall accuracy could only reach $74.44 \%$. As a result, neither vibration-based nor current-based analysis is unable to identify the motor conditions with acceptable accuracy, and the integration of vibration and current information is required.

4.4. Comparison of SVM Parameters. In addition to the linear kernel function, Gaussian kernel and polynomial kernel have been used to implement the kernel SVM. A third-order polynomial is used for the polynomial kernel, while the parameters $\mathrm{C}$ and $\gamma$ are chosen as 40 and 0.125 for the Gaussian kernel after optimization. The classification results of these kernels are shown in Tables 6 and 7 .

It could be seen that the Gaussian kernel has the highest accuracy of $66.67 \%$ for the vibration signal, but it is merely about $1 \%$ higher than that of the linear kernel. Besides, the linear kernel has the highest accuracy of $74.44 \%$ for the current signal. Hence, the linear SVM was selected to analyse both the vibration and current signals for consistency.

4.5. Comparison of Classifiers. K-nearest neighbours (KNN) and artificial neural network (ANN) were implemented in addition to the linear kernel SVM [53]. The number of nearest neighbours $k=1$ was selected into the KNN model, and a signal hidden layer of 8 neurons was applied for the ANN model heuristically. All the features, four features from the vibration signal and eight features from the current signal, were identical. The results are shown in Tables 8 and 9. It is seen that even though the ANN has an edge over the SVM regarding the vibration signal, the SVM outperforms other classifiers completely for the current signal. Hence, we stick to the linear kernel SVM for the decision-level data fusion.

4.6. Diagnosis Based on Decision-Level Data Fusion. From the aforementioned discussion, it could be concluded that the analyses based on the vibration and current signals have their strengths and weaknesses. The vibration analysis identified the inner ring and outer ring defects accurately, while the current analysis was most sensitive to the broken rotor bar. Both of them have a low classification rate regarding the misalignment and the normal condition. Therefore, a decision-level data fusion scheme based on the fuzzy integrals was proposed to integrate the information from both the vibration and current signals to produce higher classification accuracy than any individual data source, as shown in Figure 2.

In this scheme, the previous vibration and current analysis, which included the feature extraction and classification, remains. The classification results obtained from each SVM classifier and the distance to the hyperplane of each faulty category are used to fuse two data sources. The distance to the hyperplane of each faulty category was calculated and is shown in Figure 17.

The first step of data fusion is to define the membership degree which could be used as a set function to calculate the fuzzy integral. The membership degree represents the degree of accuracy. The value of subset $x$ equaling 0 means $x$ is not a member of the fuzzy set, while the value of subset $x$ equaling 1 means $x$ is a member of the fuzzy set. In this study, the distance to the hyperplane of each faulty category $D$ was used to define the membership degree $M$, as shown in equation (15). The values of the membership degree are set to the values of $D$ for $0.5 \leq D \leq 1$. Otherwise, the values of the membership degree are set to 0.5 :

$$
\begin{aligned}
& D=1-\frac{\left|0.5\left(D_{\text {mean }}-D_{\text {testing }}\right)\right|}{D_{\text {mean }}}, \\
& M= \begin{cases}D, & 0.5 \leq D \leq 1, \\
0.5, & D<0.5,\end{cases}
\end{aligned}
$$

where $D_{\text {testing }}$ is the distance of the testing data point to the hyperplane and $D_{\text {mean }}$ is the mean distance of the training data to the hyperplane for the specific condition.

The second step of data fusion is to determine the fuzzy measure values based on the results of the SVM. The fuzzy measure could be defined as the degree of reliability of the classification result. By looking at the first raw data in Tables 8 and 9 simultaneously, it can be seen that the classification accuracy of the normal condition only has $33.33 \%$ of the vibration signal and $77.78 \%$ of the current signal. Because the result of current analysis is more reliable than that of the vibration analysis, their fuzzy measures of the normal condition are set to 0.78 and 0.33 . Likewise, the fuzzy measures of misalignment are set to 0.72 for the current analysis and 0.39 for the vibration analysis. The fuzzy measures of the BRB in the current analysis and inner ring fault and outer ring fault in the vibration analysis were set to 
TABle 4: Classification accuracies of the vibration signal (\%).

\begin{tabular}{|c|c|c|c|c|c|c|c|}
\hline Number of features & Normal & $\mathrm{BRB}$ & MIS & IRF & ORF & Average & Excluded features \\
\hline 9 & 33.33 & 55.56 & 38.89 & 100 & 100 & 65.56 & - \\
\hline 8 & 33.33 & 55.56 & 38.89 & 100 & 100 & 65.56 & $\mathrm{ME}$ \\
\hline 4 & 33.33 & 55.56 & 38.89 & 100 & 100 & 65.56 & ME, SD, RMS, VAR, WF \\
\hline 3 & 11.11 & 61.11 & 27.78 & 100 & 100 & 60.00 & ME, SD, RMS, VAR, WF, KU \\
\hline
\end{tabular}

TABLE 5: Classification accuracies of the current signal (\%).

\begin{tabular}{|c|c|c|c|c|c|c|c|}
\hline Number of features & Normal & $\mathrm{BRB}$ & MIS & IRF & ORF & Average & Excluded features \\
\hline 9 & 66.67 & 100 & 55.56 & 61.11 & 66.67 & 70.00 & - \\
\hline 8 & 77.78 & 100 & 72.22 & 61.11 & 61.11 & 74.44 & KU \\
\hline 7 & 72.22 & 100 & 72.22 & 61.11 & 61.11 & 73.33 & KU, VAR \\
\hline 6 & 66.67 & 100 & 66.67 & 61.11 & 61.11 & 71.11 & KU, VAR, ME \\
\hline 5 & 66.67 & 100 & 72.22 & 55.56 & 61.11 & 71.11 & KU, VAR, ME, SD \\
\hline 4 & 55.56 & 100 & 72.22 & 55.56 & 66.67 & 70.00 & KU, VAR, ME, SD, RMS \\
\hline
\end{tabular}

TABle 6: Classification accuracy of the vibration signal by different SVM kernels (\%).

\begin{tabular}{lcccccc}
\hline SVM kernel & Normal & BRB & MIS & IRF & ORF & Average \\
\hline Linear & 33.33 & 55.56 & 38.89 & 100 & 100 & 65.56 \\
Polynomial & 77.78 & 11.11 & 72.22 & 100 & 66.67 & 65.56 \\
Gaussian & 38.89 & 16.67 & 77.78 & 100 & 100 & 66.67 \\
\hline
\end{tabular}

TABLE 7: Classification accuracy of the current signal by different SVM kernels (\%).

\begin{tabular}{lcccccc}
\hline SVM kernel & Normal & BRB & MIS & IRF & ORF & Average \\
\hline Linear & 77.78 & 100 & 72.22 & 61.11 & 61.11 & 74.44 \\
Polynomial & 61.11 & 100 & 33.33 & 38.89 & 55.56 & 57.78 \\
Gaussian & 61.11 & 100 & 33.33 & 55.56 & 66.67 & 63.33 \\
\hline
\end{tabular}

TABLE 8: Classification accuracy of the vibration signal by different classifiers (\%).

\begin{tabular}{lcccccc}
\hline Classifier & Normal & BRB & MIS & IRF & ORF & Average \\
\hline SVM & 33.33 & 55.56 & 38.89 & 100 & 100 & 65.56 \\
KNN & 61.11 & 27.78 & 55.56 & 100 & 100 & 68.89 \\
ANN & 22.22 & 55.56 & 72.22 & 100 & 100 & 69.99 \\
\hline
\end{tabular}

TABLE 9: Classification accuracy of the current signal by different classifiers (\%).

\begin{tabular}{lcccccc}
\hline Classifier & Normal & BRB & MIS & IRF & ORF & Average \\
\hline SVM & 77.78 & 100 & 72.22 & 61.11 & 61.11 & 74.44 \\
KNN & 77.78 & 100 & 44.44 & 33.33 & 55.56 & 62.22 \\
ANN & 72.22 & 100 & 22.22 & 50 & 22.22 & 53.33 \\
\hline
\end{tabular}

1 because of their high classification accuracy. The fuzzy measures of all the faulty categories are as listed in Table 10.

Once the fuzzy measure and membership degree are defined, the values of fuzzy integrals can be calculated using equation (10). The final decision-making process is generated using the initial diagnoses from different classifiers. The final decision-making process using fuzzy integral data fusion is presented in Table 11. The classification accuracies for all tests are listed in Table 12, which

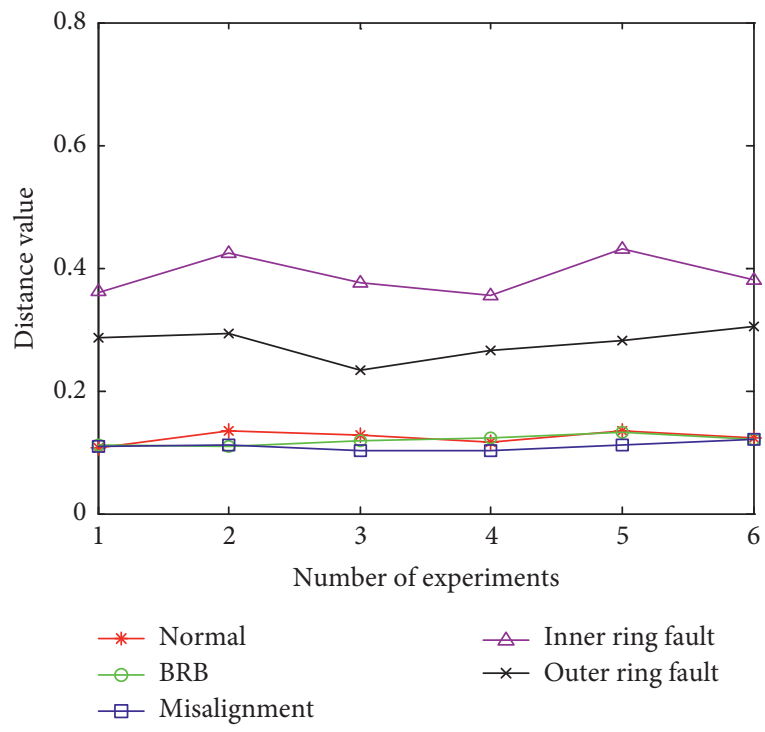

(a)

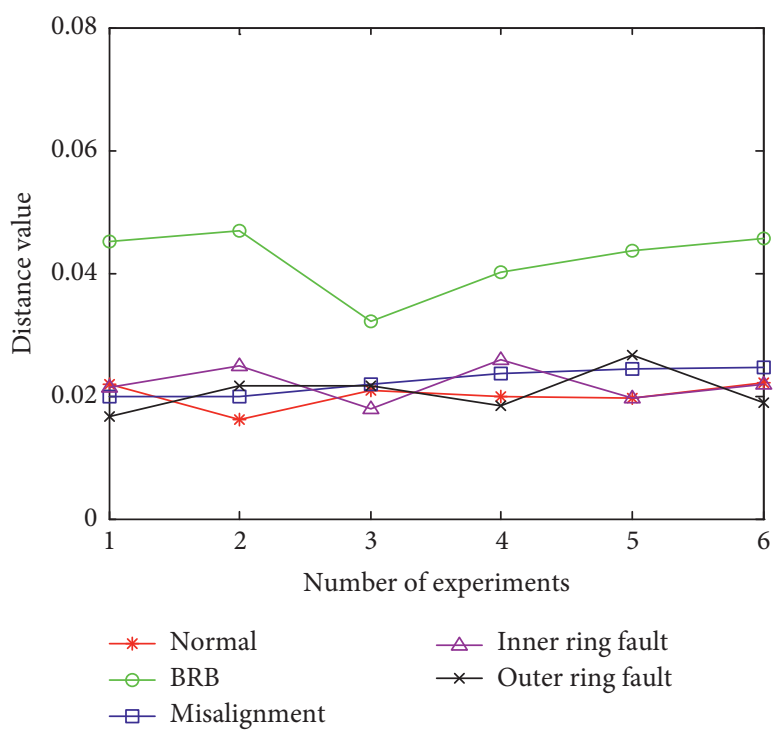

(b)

FIGURE 17: Distance of the SVM with (a) vibration data and (b) current data. 
Table 10: Definition of fuzzy measures.

\begin{tabular}{lcc}
\hline Classifier faults & SVM I (vibration signal) & SVM II (current signal) \\
\hline Normal & 0.33 & 0.78 \\
BRB & 0.5 & 1 \\
Misalignment & 0.39 & 0.72 \\
Inner ring fault & 1 & 0.5 \\
Outer ring fault & 1 & 0.5 \\
\hline
\end{tabular}

TABLE 11: Diagnosis results of fuzzy integrals.

\begin{tabular}{|c|c|c|c|c|}
\hline Fault & SVM classifier & Membership degree & Initial diagnosis & Fuzzy integrals \\
\hline \multirow{2}{*}{ Normal (N) } & 1 & 0.7784 & $\mathrm{~N}$ & \multirow{2}{*}{$0.7784(\mathrm{~N})$} \\
\hline & 2 & 0.9539 & $\mathrm{E}$ & \\
\hline \multirow{2}{*}{ Broken rotor bar $(\mathrm{BRB})$} & 1 & 0.9756 & $\mathrm{BRB}$ & \multirow{2}{*}{$0.9756(\mathrm{BRB})$} \\
\hline & 2 & 0.9715 & $\mathrm{~N}$ & \\
\hline \multirow{2}{*}{ Misalignment (E) } & 1 & 0.8869 & $\mathrm{E}$ & \multirow{2}{*}{$0.8869(\mathrm{E})$} \\
\hline & 2 & 0.9896 & $\mathrm{~N}$ & \\
\hline \multirow{2}{*}{ Inner ring fault (I) } & 1 & 0.9894 & $\mathrm{O}$ & \multirow{2}{*}{$0.9923(\mathrm{I})$} \\
\hline & 2 & 0.9923 & I & \\
\hline \multirow{2}{*}{ Outer ring fault $(\mathrm{O})$} & 1 & 0.9029 & $\mathrm{~N}$ & \multirow{2}{*}{$0.9476(\mathrm{O})$} \\
\hline & 2 & 0.9476 & $\mathrm{O}$ & \\
\hline
\end{tabular}

TABLE 12: Classification accuracy of the fusion scheme.

\begin{tabular}{|c|c|c|c|c|c|c|}
\hline & & \multicolumn{5}{|c|}{ Faulty condition of the motor } \\
\hline & & Normal & $\mathrm{BRB}$ & MIS & IRF & ORF \\
\hline \multirow{5}{*}{ Results of prediction } & Normal & 15 & 0 & 0 & 0 & 0 \\
\hline & BRB & 1 & 18 & 1 & 0 & 0 \\
\hline & MIS & 0 & 0 & 15 & 0 & 0 \\
\hline & IRF & 0 & 0 & 2 & 18 & 0 \\
\hline & ORF & 2 & 0 & 0 & 0 & 18 \\
\hline Accuracy (\%) & & 83.33 & 100 & 83.33 & 100 & 100 \\
\hline Total accuracy (\%) & & \multicolumn{5}{|c|}{93.33} \\
\hline
\end{tabular}

shows the prediction accuracy is significantly increased to 93.33\%.

\section{Conclusion}

This research has discussed the diagnosis of the induction motor from two different perspectives: vibration and current analysis. In general, both the vibration-based and currentbased diagnoses have their strengths and weaknesses. For the vibration-based diagnosis, the data acquisition of multiple accelerometers from various locations could help identify the fault location accurately, but this would increase the overall cost on the hardware and software. The diagnosis accuracy is significantly affected by the noise, input disturbance, and resonance. To receive the most accurate measurement of the vibration signal, the accelerometers must be fixed to the shaft holder intrusively. However, most practices attach the accelerometers to the equipment's surface and hence hinder the transmission of the highfrequency vibration. Simply put, the current transducers used in the current-based diagnosis are nonintrusive and could be installed on the power source, thus preventing the sensors from being damaged by the hazardous environment. Nonetheless, the motor loading must be large enough to make the fault characteristic frequency significant on the current spectrum. To overcome the deficiency of vibrationbased and current-based diagnoses, this research proposed a sensor fusion scheme to integrate the information of vibration and current signals. The contributions of this research are listed as follows:

(i) The commonly used statistical indexes were applied to the WPD coefficients related to the specific bandwidths, such as the resonant frequency of the vibration signal and the fault characteristic frequencies of the current signal, to generate features for the support vector machines. Through the feature selection process, it was found that skewness, maximum value, crest factor, and kurtosis of the WPD coefficients are the most significant features for the vibration analysis, while skewness, crest factor, waveform factor, maximum value, root mean square, standard deviation, mean, and variance of the WPD coefficients are the most significant features for the current analysis.

(ii) Both mechanical and electrical faults were reproduced in the experiment. Five conditions including the healthy condition, broken rotor bar, coupling 
misalignment, inner ring fault, and outer ring fault were considered. The WPD coefficients of vibration and current signals showed distinct patterns with regard to different conditions. It was found that the vibration-based diagnosis has a better performance regarding the mechanical faults, while the currentbased diagnosis is more sensitive to the electrical faults.

(iii) The performances of k-nearest neighbours, artificial neural network, and support vector machines of different kernels were compared. It was shown that the artificial neural network had the best classification accuracy in the vibration analysis, but its edge over the other classifiers was small. On the contrary, the linear kernel support vector machine outperformed the other classifiers in the current analysis.

(iv) The Sugeno fuzzy integral was adopted to perform the decision-level data fusion of the vibration and current signals. The distance to the SVM hyperplane of each faulty category was used to define the membership degree, and the fuzzy measure between the vibration and current analysis was determined by the classification accuracy of the linear kernel SVM. The fusion result indicated that integrating the information from the vibration-based and the current-based diagnosis at the decision level could well improve the accuracy of the overall diagnosis.

Future development of this diagnosis architecture could include more electrical faults of the induction motor, such as the faults induced by the converter, inverter, and variable frequency drive.

\section{Data Availability}

The data used to support the findings of this study are available from the corresponding author upon request.

\section{Conflicts of Interest}

The authors declare that there are no conflicts of interest regarding the publication of this paper.

\section{Acknowledgments}

This work was financially supported by the "Center for Cyber-Physical System Innovation" from The Featured Areas Research Center Program within the framework of the Higher Education Sprout Project by the Ministry of Education (MOE) in Taiwan. Part of the funding also came from the Ministry of Science and Technology (MOST) in Taiwan under Grant no. MOST 107-2221-E-011-139.

\section{References}

[1] R. K. Mobley, An Introduction to Predictive Maintenance, Butterworth-Heinemann, Oxford, UK, 2002.

[2] R. K. Mobley, Vibration Fundamentals, Butterworth-Heinemann, Oxford, UK, 1999.
[3] S. J. Lacky, "An overview of bearing vibration analysis," Maintenance \& Asset Management, vol. 23, no. 6, pp. 32-42, 2008.

[4] S. Jeevanand and A. T. Mathew, "Condition monitoring of induction motors using wavelet based analysis of vibration signals," in Proceedings of the 2008 Second International Conference on Future Generation Communication and Networking Symposia, vol. 3, IEEE, Sanya, China, December 2008.

[5] B. P. Graney and K. Starry, "Rolling element bearing analysis," Materials Evaluation, vol. 70, no. 1, 2012.

[6] Q. Hu, Z. He, Z. Zhang, and Y. Zi, "Fault diagnosis of rotating machinery based on improved wavelet package transform and SVMs ensemble," Mechanical Systems and Signal Processing, vol. 21, no. 2, pp. 688-705, 2007.

[7] D. Wang, Q. Miao, X. Fan, and H.-Z. Huang, "Rolling element bearing fault detection using an improved combination of Hilbert and wavelet transforms," Journal of Mechanical Science and Technology, vol. 23, no. 12, pp. 3292-3301, 2009.

[8] Z. Wei, J. Gao, X. Zhong, Z. Jiang, and B. Ma, "Incipient fault diagnosis of rolling element bearing based on wavelet packet transform and energy operator," WSEAS Transactions on Systems, vol. 10, no. 3, pp. 81-90, 2011.

[9] J. Lee, F. Wu, W. Zhao, M. Ghaffari, L. Liao, and D. Siegel, "Prognostics and health management design for rotary machinery systems-reviews, methodology and applications," Mechanical Systems and Signal Processing, vol. 42, no. 1-2, pp. 314-334, 2014.

[10] P. G. Kulkarni and A. D. Sahasrabudhe, "Application of wavelet transform for fault diagnosis of rolling element bearings," International Journal of Technology Enhancements and Emerging Engineering Research, vol. 2, no. 4, pp. 138-148, 2013.

[11] J. Ma, J. Wu, X. Wang, Y. Fan, and T. Leng, "A fault detection method of rolling bearing based on wavelet packet-cepstrum," Research Journal of Applied Sciences, Engineering and Technology, vol. 5, no. 12, pp. 3402-3406, 2013.

[12] W. Ma and L. Meng, "Fault pattern recognition of rolling bearings based on wavelet packet and support vector machine," in Proceedings of the IEEE 27th Chinese Control Conference, IEEE, Kunming, China, July 2008.

[13] Y. Lei, J. Lin, Z. He, and Y. Zi, "Application of an improved kurtogram method for fault diagnosis of rolling element bearings," Mechanical Systems and Signal Processing, vol. 25, no. 5, pp. 1738-1749, 2011.

[14] X. Chen, F. Feng, and B. Zhang, "Weak fault feature extraction of rolling bearings based on an improved kurtogram," Sensors, vol. 16, no. 9, 1482 pages, 2016.

[15] D. Wang, P. W. Tse, and K. L. Tsui, "An enhanced Kurtogram method for fault diagnosis of rolling element bearings," Mechanical Systems and Signal Processing, vol. 35, no. 1-2, pp. 176-199, 2013.

[16] S. Fang and Z. Wei, "Rolling bearing fault diagnosis based on wavelet packet and rbf neural network," in Proceedings of the IEEE 2007 Chinese Control Conference, IEEE, Hunan, China, July 2007.

[17] J. Chebil, "Wavelet decomposition for the detection and diagnosis of faults in rolling element bearings," Jordan Journal of Mechanical and Industrial Engineering, vol. 3, no. 4, pp. 260-267, 2009.

[18] S. Abbasion, A. Rafsanjani, A. Farshidianfar, and N. Irani, "Rolling element bearings multi-fault classification based on the wavelet denoising and support vector machine," $\mathrm{Me}$ chanical Systems and Signal Processing, vol. 21, no. 7, pp. 2933-2945, 2007. 
[19] P. Konar and P. Chattopadhyay, "Bearing fault detection of induction motor using wavelet and support vector machines (SVMs)," Applied Soft Computing, vol. 11, no. 6, pp. 42034211, 2011.

[20] A. Khezzar, M. El Kamel Oumaamar, M. Hadjami, M. Boucherma, and H. Razik, "Induction motor diagnosis using line neutral voltage signatures," IEEE Transactions on Industrial Electronics, vol. 56, no. 11, pp. 4581-4591, 2009.

[21] H. Çaliş and A. Çakir, "Experimental study for sensorless broken bar detection in induction motors," Energy Conversion and Management, vol. 49, no. 4, pp. 854-862, 2008.

[22] H. Çaliş and A. Çakir, "Rotor bar fault diagnosis in three phase induction motors by monitoring fluctuations of motor current zero crossing instants," Electric Power Systems Research, vol. 77, no. 5-6, pp. 385-392, 2007.

[23] W. T. Thomson and R. J. Gilmore, "Motor current signature analysis to detect faults in induction motor drives-fundamentals, data interpretation, and industrial case histories," in Proceedings of the 32nd Turbomachinery Symposium, Texas A\&M University, College Station, TX, USA, September 2003.

[24] E. L. Bonaldi, L. E. L. de Oliveira, J. G. Borges da Silva, G. Lambert-Torres, and L. E. Borges da Silva, "Predictive maintenance by electrical signature analysis to induction motors," in Induction Motors-Modelling and Control, pp. 487-520, INTECH Open Access Publisher, Rijeka, Croatia, 2012.

[25] D. Miljković, "Brief review of motor current signature analysis," HDKBR Info Magazine, vol. 5, no. 1, pp. 14-26, 2015.

[26] A. Luchetta, S. Manetti, M. C. Piccirilli et al., "MLMVNNN for parameter fault detection in PWM DC-DC converters and its applications for buck and boost DC-DC converters," IEEE Transactions on Instrumentation and Measurement, vol. 68, no. 2, pp. 439-449, 2019.

[27] M. Catelani, L. Ciani, A. Reatti et al., "Reliability analysis and electrical characterization of a class-e resonant inverter," in Proceedings of the IEEE International Instrumentation and Measurement Technology Conference, pp. 14-17, IEEE, Houston, TX, USA, May 2018.

[28] C. Kar and A. R. Mohanty, "Monitoring gear vibrations through motor current signature analysis and wavelet transform," Mechanical Systems and Signal Processing, vol. 20, no. 1, pp. 158-187, 2006.

[29] Z. Ye, B. Wu, and A. Sadeghian, "Current signature analysis of induction motor mechanical faults by wavelet packet decomposition," IEEE Transactions on Industrial Electronics, vol. 50, no. 6, pp. 1217-1228, 2003.

[30] J. CusidÓCusido, L. Romeral, J. A. Ortega, J. A. Rosero, and A. G. Espinosa, "Fault detection in induction machines using power spectral density in wavelet decomposition," IEEE Transactions on Industrial Electronics, vol. 55, no. 2, pp. 633-643, 2008.

[31] A. Bouzida, O. Touhami, R. Ibtiouen, A. Belouchrani, M. Fadel, and A. Rezzoug, "Fault diagnosis in industrial induction machines through discrete wavelet transform," IEEE Transactions on Industrial Electronics, vol. 58, no. 9, pp. 4385-4395, 2011.

[32] A. Widodo and B. S. Yang, "Wavelet support vector machine for induction machine fault diagnosis based on transient current signal," Expert Systems with Applications, vol. 35, no. 1-2, pp. 307-316, 2008.

[33] H. Keskes, A. Braham, and Z. Lachiri, "Broken rotor bar diagnosis in induction machines through stationary wavelet packet transform and multiclass wavelet SVM," Electric Power Systems Research, vol. 97, pp. 151-157, 2013.
[34] S. E. Pandarakone, Y. Mizuno, and H. Nakamura, "Distinct fault analysis of induction motor bearing using frequency spectrum determination and support vector machine," IEEE Transactions on Industry Applications, vol. 53, no. 3, pp. 3049-3056, 2017.

[35] E. Artigao, S. Koukoura, A. Honrubia-Escribano, J. Carroll, A. McDonald, and E. Gómez-Lázaro, "Current signature and vibration analyses to diagnose an in-service wind turbine drive train," Energies, vol. 11, no. 4, p. 960, 2018.

[36] Z. Hu, Y. Chai, X. He, and X. Xu, "Fusion of multi-class support vector machines for fault diagnosis," in Proceedings of the 2005 American Control Conference, IEEE, Portland, OR, USA, June 2005.

[37] G. Niu, A. Widodo, J.-D. Son, B.-S. Yang, D.-H. Hwang, and D.-S. Kang, "Decision-level fusion based on wavelet decomposition for induction motor fault diagnosis using transient current signal," Expert Systems with Applications, vol. 35, no. 3, pp. 918-928, 2008.

[38] M. S. Safizadeh and S. K. Latifi, "Using multi-sensor data fusion for vibration fault diagnosis of rolling element bearings by accelerometer and load cell," Information Fusion, vol. 18, pp. 1-8, 2014.

[39] L.-L Jiang, H.-K. Yin, X.-J. Li, and S.-W. Tang, "Fault diagnosis of rotating machinery based on multi-sensor information fusion using SVM and time-domain features," Shock and Vibration, vol. 2014, Article ID 418178, 8 pages, 2014.

[40] X. Liu, L. Ma, and J. Mathew, "Machinery fault diagnosis based on fuzzy measure and fuzzy integral data fusion techniques," Mechanical Systems and Signal Processing, vol. 23, no. 3, pp. 690-700, 2009.

[41] J.-D. Wu and C.-H. Liu, "An expert system for fault diagnosis in internal combustion engines using wavelet packet transform and neural network," Expert Systems with Applications, vol. 36, no. 3, pp. 4278-4286, 2009.

[42] A. Tabrizi, L. Garibaldi, A. Fasana, and S. Marchesiello, "Early damage detection of roller bearings using wavelet packet decomposition, ensemble empirical mode decomposition and support vector machine," Meccanica, vol. 50, no. 3, pp. 865-874, 2015.

[43] W. Caesarendra, B. Kosasih, K. Tieu, and C. A. S. Moodie, “An application of nonlinear feature extraction-a case study for low speed slewing bearing condition monitoring and prognosis," in Proceedings of the IEEE/ASME International Conference on Advanced Intelligent Mechatronics (AIM), IEEE, Wollongong, NSW, Australia, July 2013.

[44] W. Caesarendra and T. Tjahjowidodo, "A review of feature extraction methods in vibration-based condition monitoring and its application for degradation trend estimation of lowspeed slew bearing," Machines, vol. 5, no. 4, p. 21, 2017.

[45] J. M. Keller and J. Osborn, "Training the fuzzy integral," International Journal of Approximate Reasoning, vol. 15, no. 1, pp. 1-24, 1996.

[46] M. Sugeno, "Fuzzy measures and fuzzy integrals: a survey," in Fuzzy Automata and Decision Processes, pp. 89-102, North Holland Publishing Co. New York, NY, USA, 1977.

[47] P.-Y. Weng and M.-K Liu, "Roller bearing fault diagnosis based on wavelet packet decomposition and support vector machine," in Proceedings of the 2017 International Conference on Applied System Innovation (ICASI), pp. 33-36, IEEE, Sapporo, Japan, May 2017.

[48] F. Al-Badour, M. Sunar, and L. Cheded, "Vibration analysis of rotating machinery using time frequency analysis and wavelet 
techniques," Mechanical Systems and Signal Processing, vol. 25, no. 6, pp. 2083-2101, 2011.

[49] H. S. Kumar, P. Srinivasa Pai, N. S. Sriram, and G. S. Vijay, "Selection of mother wavelet for effective wavelet transform of bearing vibration signals," Advanced Materials Research, vol. 1039, pp. 169-176, 2014.

[50] X. Chiementin, B. Kilundu, J. P. Dron, P. Dehombreux, and K. Debray, "Effect of cascade methods on vibration defects detection," Journal of Vibration and Control, vol. 17, no. 4, pp. 567-577, 2011.

[51] J. Zarei and J. Poshtan, "Bearing fault detection using wavelet packet transform of induction motor stator current," Tribology International, vol. 40, no. 5, pp. 763-769, 2007.

[52] I. Guyon, J. Weston, S. Barnhill, and V. Vapnik, "Gene selection for cancer classification using support vector machines," Machine Learning, vol. 46, no. 1-3, pp. 389-422, 2002.

[53] A. Moosavian, H. Ahmadi, A. Tabatabaeefar, and M. Khazaee, "Comparison of two classifiers; K-nearest neighbor and artificial neural network, for fault diagnosis on a main engine journal-bearing," Shock and Vibration, vol. 20, no. 2, pp. 263-272, 2013. 


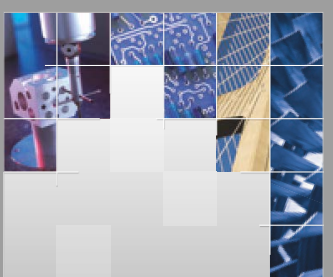

\section{Enfincering}
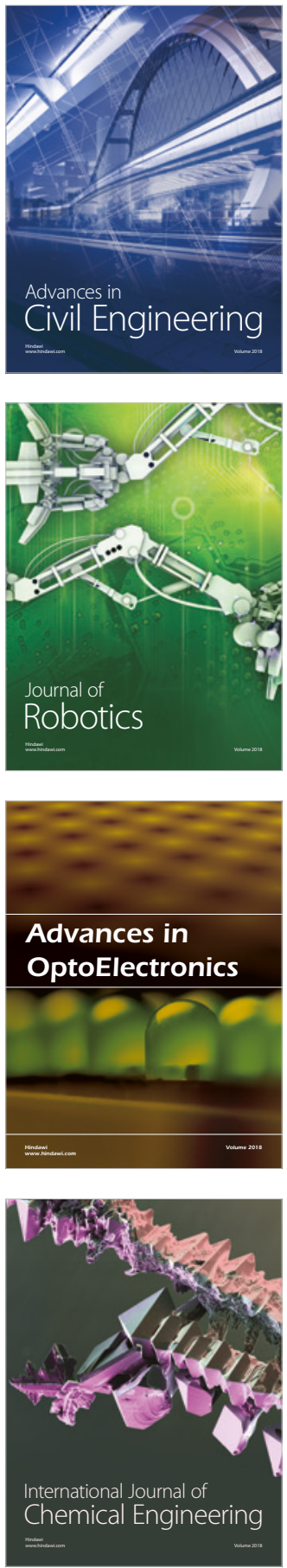

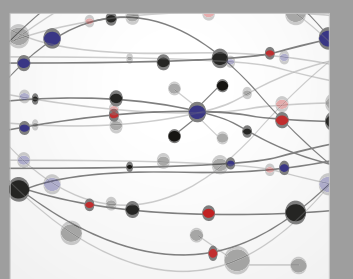

\section{Rotating \\ Machinery}

The Scientific World Journal

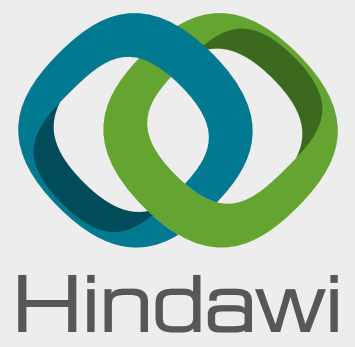

Submit your manuscripts at

www.hindawi.com
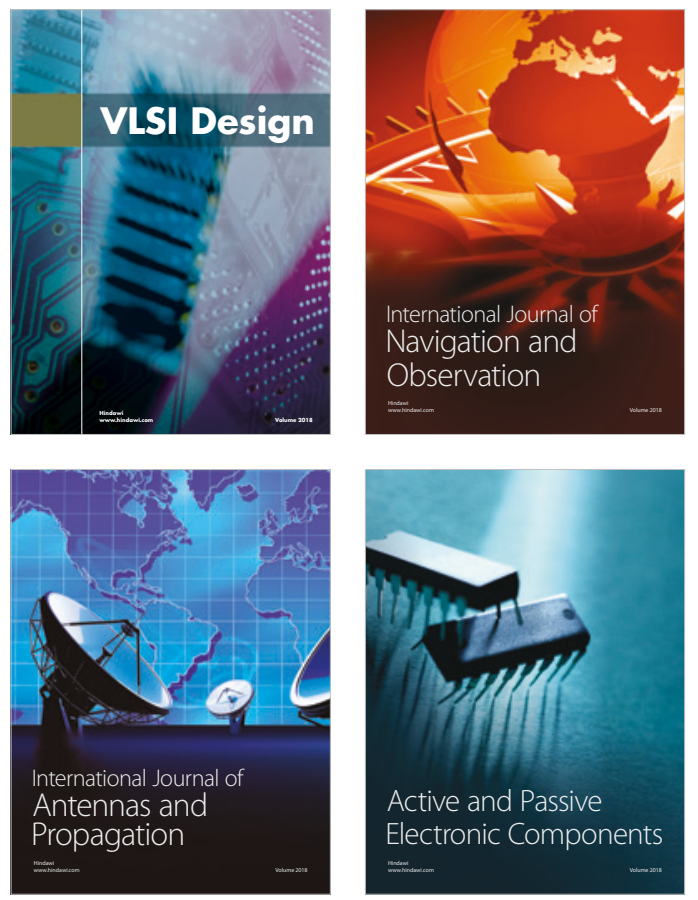
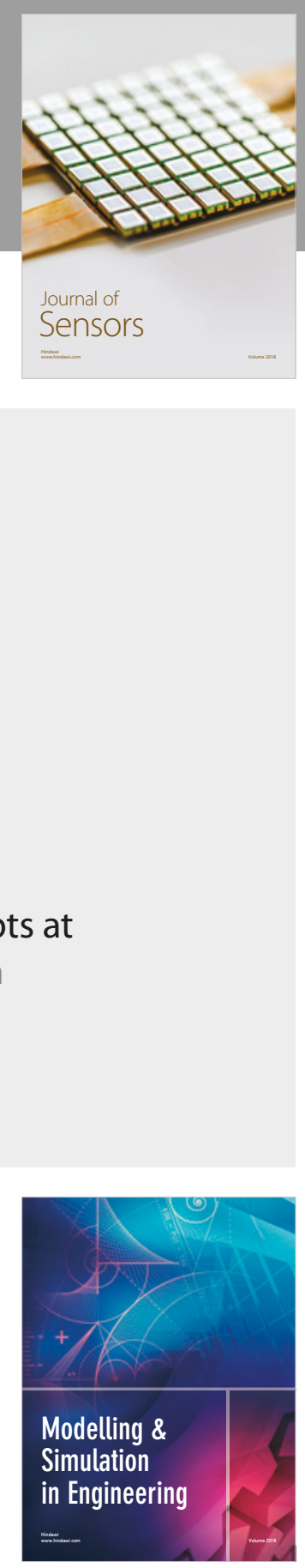

\section{Advances \\ Multimedia}
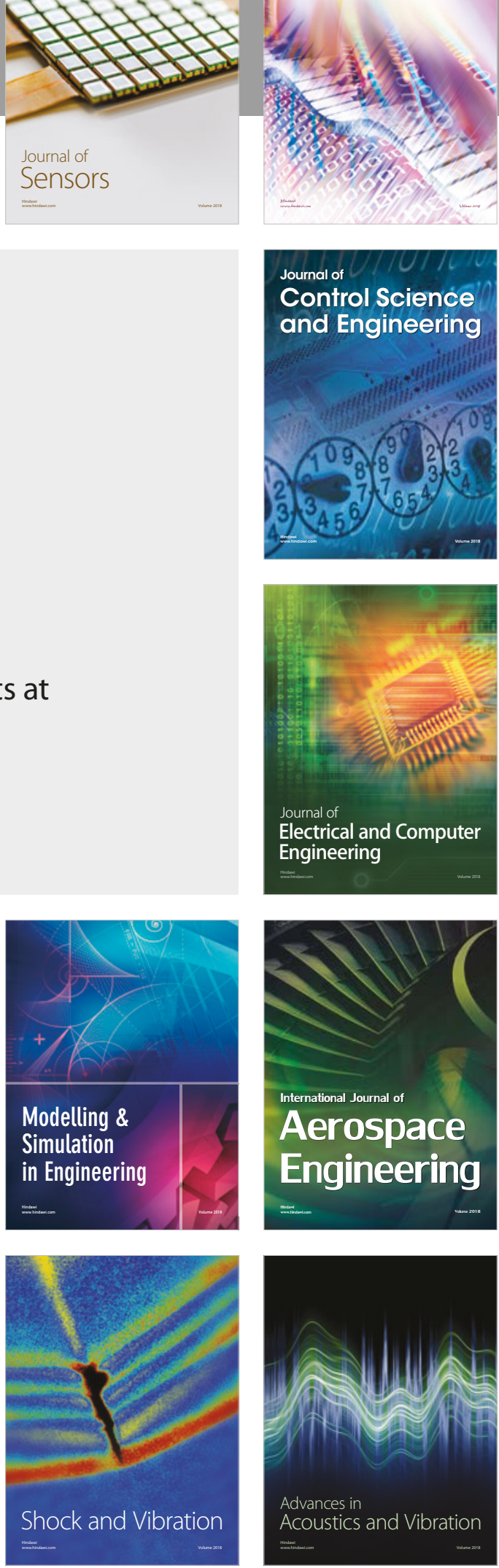